\title{
Learning Through Exploration: How Children, Adults, and Older Adults Interact with a New Feature-Rich Application \\ Shareen Mahmud
}

BSc., North South University, 2016

\section{A THESIS SUBMITTED IN PARTIAL FULFILLMENT OF THE REQUIREMENTS FOR THE DEGREE OF}

MASTER OF SCIENCE

in

The Faculty of Graduate and Postdoctoral Studies

(Computer Science)

THE UNIVERSITY OF BRITISH COLUMBIA

(Vancouver)

October 2019

(c) Shareen Mahmud, 2019 
The following individuals certify that they have read, and recommend to the Faculty of Graduate and Postdoctoral Studies for acceptance, the thesis entitled:

Learning Through Exploration: How Children, Adults, and Older Adults Interact with a New Feature-Rich Application

submitted by Shareen Mahmud in partial fulllment of the requirements

for the degree of Master of Science in Computer Science

Examining Committee:

Joanna McGrenere, Computer Science

Supervisor

Reid Holmes, Computer Science

Supervisory Committee Member 


\section{Abstract}

Feature-rich applications such as word processors and spreadsheets are not only being used by working adults but increasingly also used by children and older adults in highly varied contexts. Learning these applications is challenging as they offer hundreds of commands throughout the interface. We investigate how newcomers from different age groups explore the user interface of a feature-rich application to determine, locate and use relevant features. We conducted an in-lab observational study with 10 children (10-12), 10 adults (20-35) and 10 older adults (60-75) who were all first-time users of Microsoft OneNote. Our results illustrate key exploration differences across age groups, including that children were careful and performed as efficiently as the adults, although they struggled to locate contextual menus, whereas older adults spent a longer time and repeated sequences of failed selections. Further, older adults' exploration style was negatively influenced by their past knowledge of similar applications. We discuss design interventions for HCI to better accommodate the age-related differences in exploration styles when users interact with a feature-rich application for the first time. 


\section{Lay Summary}

Feature-rich applications (e.g., Microsoft Word) are complex software that provide users with hundreds of commands organized under different menus. Users often learn these applications by exploring the features displayed on the user interface. However, this can be challenging as users must determine, locate, and make use of the relevant features for their tasks. Today, these applications are being used by children, adults, and older adults with different past experiences with technology. We observed how 10 children (10-12), 10 adults (20-35), and 10 older adults (60-75) explored a feature-rich application, Microsoft OneNote, for the first time. We found that children performed as well as the adults but struggled to locate the right-click menu, whereas older adults spent a longer time and selected irrelevant features multiple times. Moreover, older adults' interface exploration was negatively influenced by their past software knowledge. We discuss design ideas to accommodate the age-related differences for software newcomers. 


\section{Preface}

The study described in this thesis was conducted with the approval of the UBC Behavioural Research Ethics Board (certificate number H18-01880).

Parts of this thesis appear in a conference paper manuscript that is currently under submission, where I am the first author. I designed and conducted the user study, analyzed the data, and identified the results. The initial draft of this paper was written by me which was later revised. Dr. Joanna McGrenere provided supervisory assistance for this research and helped frame the research questions and the study procedure, as well as edited the full manuscript. Postdoctoral Fellow Jessalyn Alvina created the timeline data visualization and significantly contributed to writing the data analysis and results sections. Drs. Parmit Chilana and Andrea Bunt provided valuable feedback throughout this research. 


\section{Table of Contents}

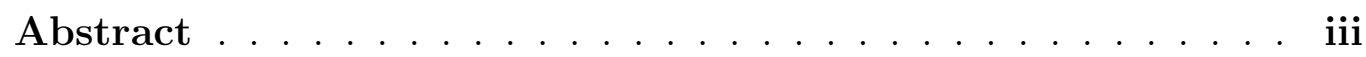

Lay Summary . . . . . . . . . . . . . . . . iv

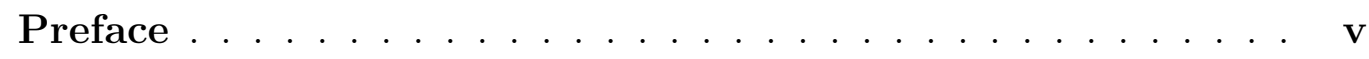

Table of Contents $\ldots \ldots \ldots \ldots \ldots \ldots \ldots$ vi

List of Figures $\ldots \ldots \ldots \ldots \ldots \ldots \ldots \ldots$ ix

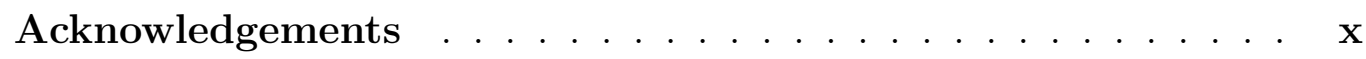

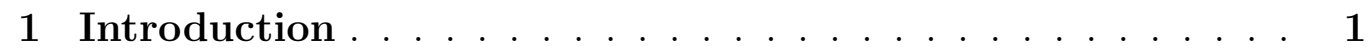

1.1 Problem Definition . . . . . . . . . . . . 1

1.2 Contributions . . . . . . . . . . . . . . . . 3

1.3 Overview . . . . . . . . . . . . . . 3

2 Related Work . . . . . . . . . . . . . . . . . 4

2.1 Users' Approaches to Learning New Applications . . . . . . . 4

2.2 Age-Related Differences in Exploratory Learning . . . . . . . . 5

2.3 Interface Guidelines to Support Age Differences . . . . . . . 7

3 User Study $\ldots \ldots \ldots \ldots \ldots$

3.1 Participants . . . . . . . . . . . . . . . . . . . 9

3.2 Apparatus . . . . . . . . . . . . . . . . 9 
3.3 Tasks . . . . . . . . . . . . . . . . . . . . . . 9

3.4 Procedure . . . . . . . . . . . . . . . . . 10

4 Data Analysis . . . . . . . . . . . . . . . . . . 13

4.1 Video Coding and Event Generation . . . . . . . . . . . 13

4.2 Timeline Visualization . . . . . . . . . . . . . . 16

4.3 Interview . . . . . . . . . . . . . . . . . . 18

4.4 Questionnaire .................... . . . 18

5 Results . . . . . . . . . . . . . . . . . . 19

5.1 Participants' Expertise and Overall Performance . . . . . . . 20

5.1.1 Adults have the most experience with different applications, children's and older adults' current software use is similar . . . . . . . . . . . . . . . 20

5.1.2 Children are almost as fast as adults, older adults are

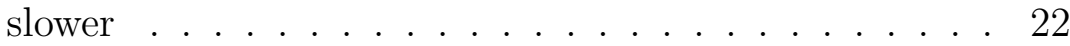

5.2 Interface Exploration Styles . . . . . . . . . . . . . . 25

5.2.1 Children and older adults face different challenges in locating relevant features . . . . . . . . . . . . 2 25

5.2.2 Older adults struggle more than children and adults to determine the relevant sequence of selections . . . . . . 27

5.2.3 Adults and older adults rely on past software experience, children rely on real-life experience . . . . . . . . 31

5.2.4 Tooltips can be helpful but are infrequently used by the three age groups $\ldots \ldots \ldots$. . . . . . . . . . 32

5.3 Facing Breakdowns . . . . . . . . . . . . . . . . 33

5.3.1 Children are quick at recovering from breakdowns, older adults take time . . . . . . . . . . . . . . . . 33

5.3.2 Children rely on reading when facing a breakdown, older adults try out random options . . . . . . . . . . 34

5.4 Overall Feeling and Help-Seeking Approach . . . . . . . . . 36 
5.4.1 Children and adults seem fairly content with self-exploration, older adults feel disappointment . . . . . . . . . . . 36

5.4.2 Adults prefer Google search, children and older adults prefer instructions from people or the built-in help . . . 37

6 Discussion and Implications for Design . . . . . . . . . . 39

7 Threats to Validity . . . . . . . . . . . . . . . 43

7.1 Internal Validity . . . . . . . . . . . . . . . . . 43

7.2 Construct Validity . . . . . . . . . . . . . . . . 43

7.3 External Validity . . . . . . . . . . . . . . . . . . 44

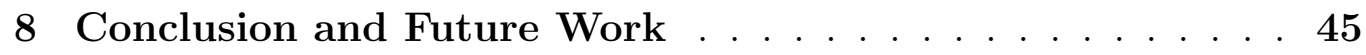

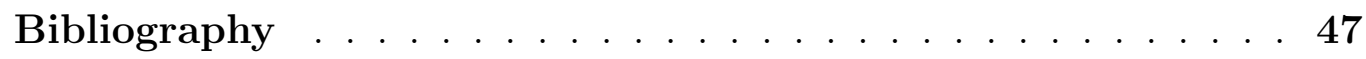

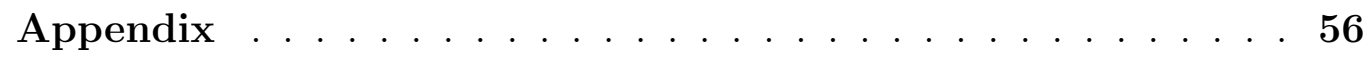

Call for Participation . . . . . . . . . . . . . . 56

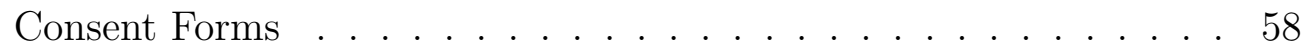

Conceptual Model . . . . . . . . . . . . . . . . . . . 6 65

Task List . . . . . . . . . . . . . . . . . . . 68

Expertise Questionnaire . . . . . . . . . . . . . 70

Self-Efficacy Questionnaire . . . . . . . . . . . . . 76 


\section{List of Figures}

3.1 The interface of Microsoft OneNote . . . . . . . . . . . 11

4.1 Final list of events tagged . . . . . . . . . . . . . . 15

4.2 Snippet of a participant's video coding file . . . . . . . . 16

4.3 Example of three timelines, one from each age group . . . . . 17

5.1 Expertise characteristics of the three age groups . . . . . . . 21

5.2 Average of the total duration per age group . . . . . . . . . . 23

5.3 Median number of selections by age group . . . . . . . . . . . 29

5.4 Example of the paths taken by O7 and O4 during a Science sub-task ....................... 30 


\section{Acknowledgements}

First and foremost, I would like to thank my supervisor, Joanna McGrenere for believing in me, taking me on as her student, and giving my life a meaningful direction. I am grateful for her endless guidance and support throughout my journey at UBC. She has always been only a message away and even on days when she has been swamped with work, she has made her students feel like a priority. Joanna's dedication and enthusiasm towards her work continue to inspire me. I simply could not have asked for a better supervisor who truly cares about her students' academic growth and well-being. I thank her for making my graduate school experience exciting and memorable.

Next, I would like to thank Jessalyn Alvina for collaborating with me on this project and acting unofficially as co-supervisor. She has been very patient with me, helping me overcome hurdles along the way and keeping my spirits up. Together, Joanna and Sally have nurtured me into a researcher and their kindness is contagious.

I would also like to thank my Software Engineering professor, Reid Holmes, for graciously accepting to be my second reader. I am grateful to all the members of the e-DAPT and SPG research groups, particularly Parmit Chilana and Andrea Bunt, for their insights that have improved this project in many ways. I am thankful to NSERC for funding this project through the Strategic Partnership Grant (STPGP 506797 - 1).

Finally, I would like to thank all the wonderful friends that I made in Vancouver who made this unknown city feel like home. I am forever indebted 
to my parents for their unconditional love and my best friend, 'Millionaire', for crossing oceans for me, quite literally. 


\section{Chapter 1}

\section{Introduction}

In this chapter, we provide an overview of the problem space related to feature-rich applications and exploratory learning. We also state the contributions of this work and outline how the rest of the work is organized into different chapters.

\subsection{Problem Definition}

Modern feature-rich applications such as word processors, spreadsheets, and 3D modeling packages offer hundreds of commands organized under various menus, toolbars, and navigation structures. These applications are powerful and highly flexible, but they can be overwhelming and difficult to learn $[1$, $2,3]$. One common way for users to learn a new application is to explore the functionality displayed on the user interface $[4,5]$. However, exploring the interface of a feature-rich application can be challenging because users must determine which features are needed to accomplish their tasks, understand how individual features work (in isolation and together), and locate relevant features in the interface $[6,7]$.

The exploratory learnability problem can be particularly acute for newcomers which often include a diverse group of users such as children and older 
adults, with varying past software experiences. While prior work has shown that people often carry out self-directed exploration to learn new software $[8,9]$, the ways in which different user groups engage in interface exploration has not been sufficiently investigated in the context of feature-rich applications.

Children are increasingly using productivity and learning applications in digital classrooms $[10,11]$. With greater flexibility in retirement age, older adults $(65+)$ are working longer and learning to use new applications for knowledge work $[12,13,14]$. As young children to older adults now use feature-rich applications for education, professional, and entertainment purposes, it becomes critical that we understand the challenges new users from different age groups face during self-directed exploration.

Previous work on older adults has focused on the challenges that they face while using new information technologies, for example, being fearful to explore new applications, having lower confidence levels, and being more negatively affected by errors than adults $[15,16,17]$. Children, on the other hand, can be more eager to explore than adults [18, 19]. However, little is known about the exploration styles of adults, children, and older adults during graphical user-interface exploration and the effectiveness of those styles is even less understood. With this issue in mind, our core research questions are: What are the age-related differences in users' exploration styles when using a feature-rich application for the first time? In particular, how do different user groups determine, locate, and use relevant features within the application? How do they deal with performance breakdowns? Characterizing these differences in exploration styles of different age groups could help designers make more inclusive design choices.

We conducted a structured observational study with 30 newcomers to a feature-rich application, Microsoft OneNote: 10 children (10-12), 10 adults (20-35), and 10 older adults (60-75). Our goals were to identify and characterize exploration styles of the different age groups. We captured both 
quantitative data (e.g., logged interactions) and qualitative data (e.g., retrospective assessments of what made exploration easy or difficult) to provide a holistic characterization of exploration behaviour. Based on both our quantitative and qualitative findings, we propose design implications for applications seeking to foster efficient exploration for the different age groups.

\subsection{Contributions}

Our work contributes the following:

1. The first study, to the best of our knowledge, that simultaneously investigates three age cohorts - children, adults, and older adults' interface exploration styles

2. Identification of the challenges that each age group faces when exploring the interface of a feature-rich application to accomplish a goal

3. Identification of the different strategies that each age group uses to deal with hurdles during interface exploration

4. Design implications to support efficient interface exploration for the different age groups.

\subsection{Overview}

In Chapter 2 we summarize previous work relevant to this thesis. Chapter 3 describes our user study. Chapter 4 explains our data analysis techniques and Chapter 5 outlines our results. In Chapter 6 we discuss our insights and the implications for design. Chapter 7 acknowledges the threats to validity and Chapter 8 concludes this thesis with directions for future work. 


\section{Chapter 2}

\section{Related Work}

In this chapter, we summarize prior work in understanding how users learn new applications in general, and the age-related differences when users particularly learn through exploration. We also discuss the design guidelines that are available to support different age groups. In each of these sections, we identify the gaps in existing literature that we aim to address with this work.

\subsection{Users' Approaches to Learning New Ap- plications}

Prior work has investigated the ways in which people learn to use a new application. Studies from back in the 1980s and 1990s to the late 2000s have shown that people often have difficulties learning a new application due to different past experiences with technology $[9,4,5]$. Despite the availability of online learning resources, built-in help, and manuals, people often tend to be reluctant to read and prefer to learn via self-directed exploration [8, 20, 9]. Although learning an application through interface exploration is a preferred strategy for many, users make more errors in the early stages of learning that 
can cause them to feel confused and frustrated [4]. We were motivated to explore software learnability of feature-rich applications across different user groups, and this body of prior work helped us to focus on exploration as the method of learning.

\subsection{Age-Related Differences in Exploratory Learning}

There has been work looking at various user groups' approaches to learning new applications. In case of adults, multiple studies in the past have shown how adults learn via exploration [21, 22]. For example, Carol-Ina Trudels work in the 90s focused on adults' exploration of a computer-simulated digital watch and showed that poor learners had "negative exploration strategies" where they repeated moves that had no effect, did not pay attention to feedback, and inaccurately assessed what had been learned so far [23]. Similarly, another study by Novick et al. [5] investigated the usefulness of trial \& error exploration with Microsoft Publisher, and found that adults relied on an interface's signifiers, which sometimes took them in the wrong direction.

When it comes to children, fewer studies have identified their exploration behaviors with a new application. In the context of using a Tablet, Couse $\&$ Chen found that children between the ages of 3 to 6 were able to draw using a limited version of Microsoft Word when guided by adults. They were persistent during exploration even when they encountered errors [24]. More recent work on children's use of a feature-rich 3D modeling application has provided insights on the barriers that they face when using help resources and found that children had difficulties locating the relevant UI elements and struggled to formulate help queries [25].

Significant work has also investigated how older adults learn new applications [13, 26, 27]. Some has explicitly made design recommendations to improve learning resources and reduce cognitive load [28, 29, 30]. Leung et 
al. examined how older adults learned to use a smartphone and found that participants switched between trial \& error and reading the manual, and also benefited from a task list [16]. Other studies have focused on helping older adults to use social networking [31, 32], healthcare [33, 34] and smart home $[35,36]$ applications. The above prior work has looked at different age groups approach to learning new applications in separate studies, and in different contexts, making it difficult to make direct comparisons.

Some studies have considered more than one age cohort when learning simpler applications, such as Chin \& Tat-Fu [15] who pointed out that when learning from a link recommendation system, older adults took longer to click on a link by first deciding if it was relevant or not, whereas adults were more likely to click and see it. This could be because older adults have been shown to have greater computer anxiety than adults [28]. In addition, OBrien et al., found that older adults had more difficulties attributed to insufficient prior knowledge than adults when learning to use technology in their everyday lives [37]. The closest work to ours is a study by Chimbo et. al [19] that looked at how children and adults explored a simple gaming interface and found that adults would not make a move that they were unsure about whereas children were open to trying out different actions to get ahead in the game. Although these studies look at more than one age cohort, none of them investigate three age cohorts simultaneously and provide insights on their varying needs. Furthermore, many of these studies allowed users to seek external help (e.g., through manuals, online resources, expert advice) whereas in our study, we specifically isolate age-relate differences when restricted to interface exploration. 


\subsection{Interface Guidelines to Support Age Dif- ferences}

To help designers build technology for children, Chiasson \& Gutwin [38] presented a catalog of design principles by gathering information from past research in HCI, education, and psychology. The design guidelines aimed to support children's cognitive, physical, social and emotional development. More recently, Soni et. al. [39] found conflicting guidelines in the literature such that they do not equally benefit children in different age categories. Hence, although having guidelines specifically oriented towards children are valuable, the age ranges in previous work vary considerably and more work is needed to test these guidelines across various age categories.

When it comes to designing interfaces for older adults, several studies in the HCI community $[40,41,42]$ have proposed design recommendations to address older adults' physical and cognitive needs as well as their varying experiences with technology. Darejeh \& Singh [43] conducted a systematic literature review to extract design principles for older adults. They found that novice elderly users benefited from a reduced feature set, descriptive text, appropriate graphical representation of concepts, and system feedback. In addition, they discussed some similarities in user interface design needs for older adults, young children and people with mental disorders, and called for future work to apply these design principles in practice.

Lastly, Neilson, Molich, and Shneiderman [44, 45] have proposed universal user interface design guidelines in the 1990s that have continued to be revised over the years [46]. These guidelines highlight the importance of informing users about the system state and helping them recover from errors. They are not age-specific but assume that they would be useful for different groups of users. In our work, we discuss some of our design recommendations in the context of the guidelines above and investigate the ways in which they could benefit software newcomers of particular age groups. 


\section{Chapter 3}

\section{User Study}

To address the gap in existing literature and understand how children, adults, and older adults explore the interface of a feature-rich application for the first time, we conducted an in-lab observational study. Our goal was not to test any hypothesis, but rather to observe how the participants determine, locate

and use relevant features within the interface. We also sought to understand the strategies that they use to deal with any hurdles during exploration. Lastly, we were also interested in knowing how they felt after exploring the interface and what their help-seeking preferences would be if not restricted to interface exploration. Using a mixed-method approach, we collected and analyzed both quantitative and qualitative data. Our choice of feature-rich application for the study was Microsoft OneNote. We chose OneNote for three main reasons: (1) it is a note-taking application that is being used in work settings, as well as by children in schools [11]; (2) released in 2012, it is relatively newer than other feature-rich productivity applications such as Microsoft Word and therefore, we hoped to find first-time users of OneNote from all three age cohorts; (3) it requires much less domain knowledge than feature-rich applications such as Photoshop and the conceptual model is likely to be easily understood regardless of any interface issues. 


\subsection{Participants}

We recruited 10 children (10-12), 10 adults (20-35), and 10 older adults (6075 ) with a gender balance. We selected these age ranges in order to minimize the overlap in the physical, technical, and cognitive abilities of participants. The study was advertised in a local school, university, community centers, and newspapers. All of our 30 participants were first-time users of Microsoft OneNote, comfortable with using a computer, and free of any motor impairments. Each received $\$ 20$ for their participation.

\subsection{Apparatus}

A Microsoft Surface laptop with Windows 10 and Microsoft OneNote application installed was used for the study. The Tobii Eye Tracker $4 \mathrm{C}$ was attached to the laptop to capture participants' gaze data. Tobii Ghost was used to create a gaze overlay (in the form of a blue bubble) which was recorded by the OBS Studio software as participants' interacted with OneNote throughout the study.

\subsection{Tasks}

To observe participants' exploration styles when using OneNote for the first time, we gave them a set of tasks to accomplish. They were asked to imagine that they were taking two online classes, Art and Science, for which they had to maintain a notebook. There were four main tasks: creating a new notebook, adding notes related to the Art class, adding notes related to the Science class, and sharing the notebook with a friend (Appendix A.4). The 'Create Notebook' and 'Share Notebook' tasks could ideally be completed in one step ('Minimum Selections' in Figure 5.3) whereas 'Art Task' and 'Science Task' had more complexity. The Art and Science tasks had 7 and 5 
sub-tasks respectively, consisting of, for example, drawing a flower, finding information about polar bears within OneNote, and locking the page with a password. Figure 3.1(c) shows an example of the final result for the Science task. Creating the notebook was always the first task, and sharing the notebook was always the last task so as to provide participants with a realistic flow. We counterbalanced the Art and Science tasks across participants. We iteratively refined the Art and Science tasks and ran 6 pilot participants. The pilot study helped us ensure that the tasks were comprehensible for all age groups. For example, initially we had a Math task which required participants to add an equation and generate its graph using OneNote. Our first few pilot participants, all adults, seemed to struggle with it. Hence, we changed the task as it might have been difficult for children and older adults as well. In addition, we ensured that the tasks included features under different menu areas, and could be completed within an hour.

\subsection{Procedure}

At the beginning of the study, the participants signed a consent form (Appendix A.2) and filled out an expertise questionnaire followed by a selfefficacy questionnaire [47]. The expertise questionnaire collected their demographic information and captured their level of computer and application expertise (Appendix A.5). The self-efficacy questionnaire asked the participants to rate their confidence level of using a new note-taking application under a variety of conditions (Appendix A.6). The conditions included having someone to help them get started, having used a similar application before, and being able to use the built-in help. After participants had answered the questionnaires, the eye tracker was set up. We incorporated the eye tracker after running the pilot participants where we realized how capturing gaze data could provide us with additional insights on participants' exploration behaviour. 


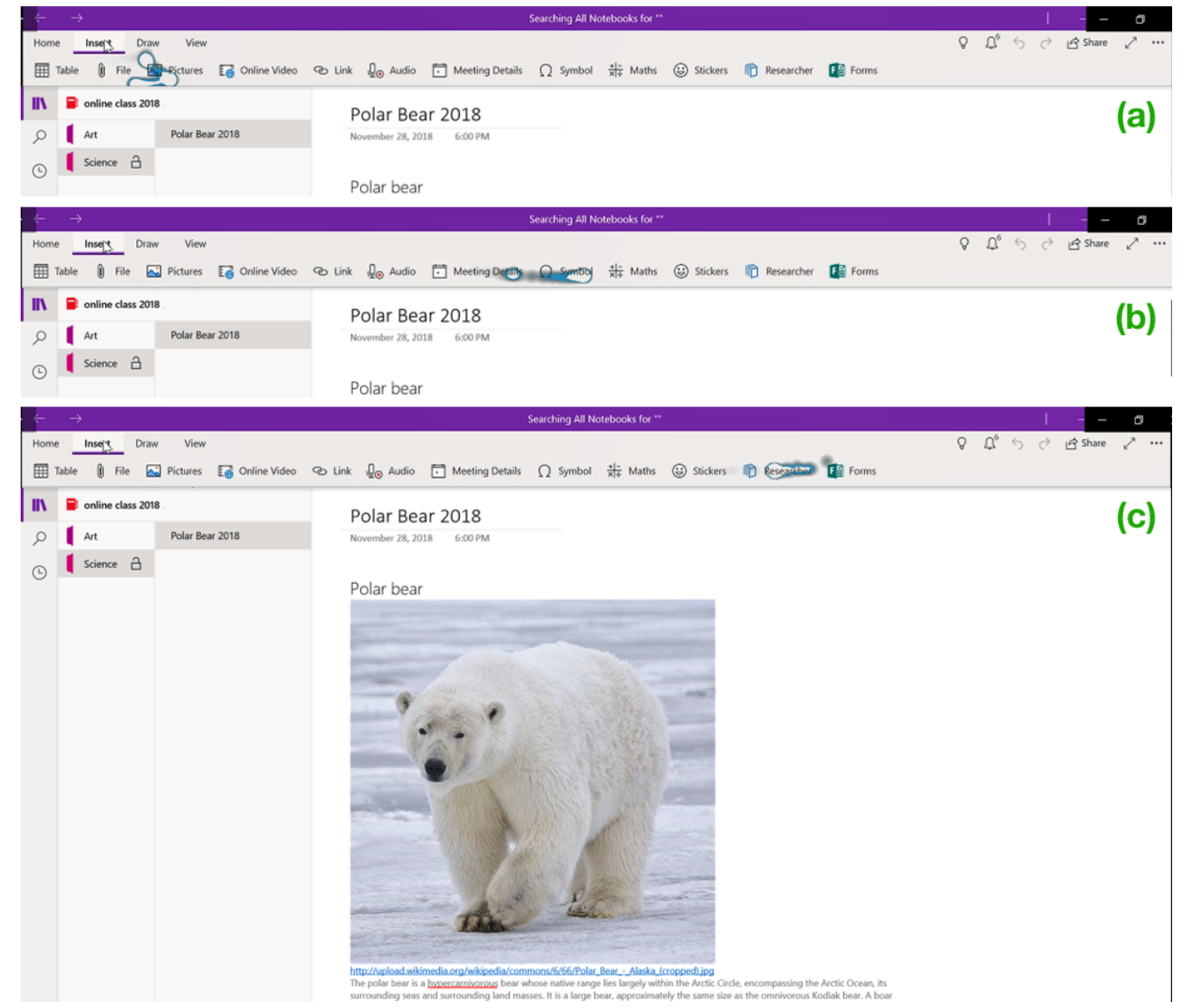

Figure 3.1: The interface of Microsoft OneNote. (a) and (b) show an example of a child participant C2's eye gaze (the blue bubble) traversing the features under the 'Insert' menu, moving from 'Pictures' (a) to 'Meeting Details' (b) and finally to 'Researcher' (c) while the mouse cursor stays on 'Insert'. The final result of the Science task is shown in (c). 
Next, we introduced participants to the conceptual model of OneNote (Appendix A.3), explaining that it is similar to a physical notebook, where one can create a notebook and add several sections and pages within that notebook. Then, we gave them the list of tasks to carry out. We encouraged the participants to explore the interface in whatever way they preferred but also told them that they were not to use external help resources. Since we had different age groups taking part in the study, we motivated them by acknowledging that the tasks were intended to be slightly difficult and that they would be given a hint if they were considerably stuck. We gave the participants a hint after 3 minutes of being stuck with a sub-task and the option to move on to the next sub-task after 5 minutes of not making any progress. Each participant had one hour to complete the four main tasks and was requested to think-aloud during the session. As participants worked on the tasks, the laptop screen was recorded along with the audio and the gaze movement.

Once the tasks were completed, for comparison purposes, participants filled out the same self-efficacy questionnaire that they answered at the beginning of the study, only this time they were asked to reflect on their experience after using OneNote. The sessions concluded with a semi-structured interview for 10 minutes where participants provided insights on their experience of using OneNote for the first time and their exploration styles. 


\section{Chapter 4}

\section{Data Analysis}

In this chapter, we discuss the procedure that we followed to code participants' screen recordings and how we used a combination of data visualization and statistics to gather insights. We also outline how we analyzed the interview and questionnaire responses.

\subsection{Video Coding and Event Generation}

We started our data analysis by coding the observational screen recordings of the participants' interaction with OneNote. The goal of the video coding was to generate and tag a set of events related to participants' exploration activities. Three members of the research team created and iterated over a codebook, with frequent references to the source videos. The codebook included events such as selecting a menu or a feature, performing an action such as typing or drawing, repeating irrelevant selections, etc. We took inspiration from Trudels [23] coding scheme of classifying exploration events when users' interacted with a digital watch and modified the event types based on the participants' interaction with OneNote. Figure 4.1 shows our codebook with the list of events tagged.

We followed the codebook to code the videos using the Boris software 
[48]. Each video had over 250 occurrences of the logged events in total. For most of these events in the codebook, we only analyzed their frequency of occurrence. For five of them that also had a time duration (including skimming and off-task actions), we analyzed the duration of each occurrence of the event. We then performed statistical analysis on the data files using the REML procedure with SAS JMP, followed by Tukey HSD tests for posthoc comparisons to understand if the number of occurrences and duration of the tagged events were different across the three age groups throughout their interaction with OneNote.

Figure 4.2 shows a snippet of the data file from a participant's coded video and illustrates how the events from the codebook were logged in the data files. For example, when the user selects the 'View' menu, the event is tagged as a selection in the 'Event Tag' column, and the 'Event Type' is categorized as an off-task selection. In addition, the amount of time that the participant takes to make this selection is noted under the 'Event Duration' column and the 'Additional Tag' column is used to provide any further details on the nature of event such as a non-unique selection. 


\begin{tabular}{|c|c|}
\hline \multicolumn{2}{|r|}{ Task Status } \\
\hline Start Task & The user starts a sub-task \\
\hline End Task & The user completes a sub-task \\
\hline Give Up & $\begin{array}{l}\text { The user is unsuccessful with the task despite } \\
\text { getting hints and has not made progress for } 5 \text { minutes }\end{array}$ \\
\hline \multicolumn{2}{|r|}{ Selection: The user clicks on a menu or feature } \\
\hline Unique & The user selects a feature for the first time \\
\hline \multicolumn{2}{|l|}{ Selection } \\
\hline Non-Unique & The user selects a feature already selected before \\
\hline \multicolumn{2}{|l|}{ Selection } \\
\hline Successful & The user selects the right feature needed for the task \\
\hline \multicolumn{2}{|l|}{ Selection* } \\
\hline $\begin{array}{l}\text { Off-Task Se- } \\
\text { lection* }\end{array}$ & The user selects a feature irrelevant to the sub-task \\
\hline $\begin{array}{l}\text { Tooltip Selec- } \\
\text { tion }\end{array}$ & $\begin{array}{l}\text { The user makes a selection after looking at the tooltip as } \\
\text { captured by eye gaze }\end{array}$ \\
\hline \multicolumn{2}{|c|}{$\begin{array}{l}\text { Perform Task: After selecting a feature, the user starts } \\
\text { any action related to executing the feature (e.g. drawing) }\end{array}$} \\
\hline $\begin{array}{l}\text { Successful } \\
\text { Action* }\end{array}$ & $\begin{array}{l}\text { The user carries out actions required to succeed in the task } \\
\text { after making a successful selection }\end{array}$ \\
\hline $\begin{array}{l}\text { Off-Task Ac- } \\
\text { tion* }\end{array}$ & $\begin{array}{l}\text { The user carries out actions insufficient to succeed in the } \\
\text { task, either after making a successful selection or by mak- } \\
\text { ing an off-task selection }\end{array}$ \\
\hline \multicolumn{2}{|r|}{ Exploration Details } \\
\hline Skim* & $\begin{array}{l}\text { The user looks at a series of features on a sub-menu but } \\
\text { does not select anything and moves on to another menu } \\
\text { (captured with eye gaze). It ends when the user makes a } \\
\text { selection or goes back to reading instructions }\end{array}$ \\
\hline $\begin{array}{l}\text { Missed Fea- } \\
\text { ture }\end{array}$ & $\begin{array}{l}\text { The user does not notice the relevant feature despite being } \\
\text { on the correct sub-menu or does not select the feature } \\
\text { despite looking at it as indicated by the eye gaze }\end{array}$ \\
\hline Unsure & $\begin{array}{l}\text { The user does not understand or notice the outcome of their } \\
\text { selection as indicated by their actions }\end{array}$ \\
\hline Retry & The user selects the same feature for the same sub-task \\
\hline Cycle & $\begin{array}{l}\text { The user repeats the same sequence of selections for the } \\
\text { same sub-task }\end{array}$ \\
\hline Right-Click & The user opens the right-click menu \\
\hline Depth & The user selects another menu \\
\hline Breadth & The user selects a feature on the same sub-menu \\
\hline Icon & The user selects a feature with only an icon \\
\hline Text & The user selects a feature with text \\
\hline Organize & The user closes tabs that are not required for the task \\
\hline Built-In Help & The user selects the built-in help \\
\hline Hint & The user gets a hint to try out a different option \\
\hline \multicolumn{2}{|c|}{ Non-Exploration Events: The user's eye gaze is not on the screen } \\
\hline $\begin{array}{l}\text { Read Instruc- } \\
\text { tions }\end{array}$ & $\begin{array}{l}\text { The user is reading task instructions or clarifying with the } \\
\text { researcher }\end{array}$ \\
\hline Idle & The user takes a break, e.g. to go to the washroom \\
\hline
\end{tabular}

Figure 4.1: Final list of events tagged. We counted the occurrence of each event. An event with $(*)$ also has a duration. 


\begin{tabular}{|c|c|c|c|c|}
\hline $\begin{array}{l}\text { Time- } \\
\text { stamp }\end{array}$ & Event Tag & $\begin{array}{l}\text { Event } \\
\text { Type }\end{array}$ & $\begin{array}{l}\text { Event } \\
\text { Duration }\end{array}$ & Additional Tag \\
\hline $11: 12$ & $\begin{array}{l}\text { Selection } \\
\text { [View] }\end{array}$ & $\begin{array}{l}\text { Off-Task } \\
\text { Selection }\end{array}$ & 2 & Non-Unique Selection \\
\hline $11: 15$ & Skim & - & 3 & - \\
\hline $11: 17$ & $\begin{array}{l}\text { Selection } \\
\text { [Insert] }\end{array}$ & $\begin{array}{l}\text { Off-Task } \\
\text { Selection }\end{array}$ & 2 & Non-Unique Selection \\
\hline $11: 25$ & $\begin{array}{l}\text { Selection } \\
\text { [Researcher] }\end{array}$ & $\begin{array}{l}\text { Successful } \\
\text { Selection }\end{array}$ & 8 & $\begin{array}{l}\text { Non-Unique, Tooltip } \\
\text { Selection }\end{array}$ \\
\hline $11: 26$ & $\begin{array}{l}\text { Perform } \\
\text { Task }\end{array}$ & $\begin{array}{l}\text { Successful } \\
\text { Action }\end{array}$ & 4 & - \\
\hline $11: 30$ & End Task & $\begin{array}{l}\text { Science } \\
\text { Sub-Task }\end{array}$ & - & - \\
\hline
\end{tabular}

Figure 4.2: Snippet of a participant's video coding file. Event duration is in seconds.

\subsection{Timeline Visualization}

To better understand how often each of the tagged events occurred during participants' interaction with OneNote and the duration of each event, we created a timeline visualization using the video coding files. The timeline categorized the events by the main tasks which helped us find contrasting patterns when we compared children, adults', older adults' timelines, and their performance on each task, with one another (Figure 4.3). Using the timeline, we were able to further identify interesting activities such as how a successful selection could be followed by an incorrectly performed action (off-task action) or how participants could repeat the same sequence of offtask selections (retries) for the same task. We ran another set of statistical analysis on the data files, using the same REML procedure as previously described, to focus on some of these events of interest per task. 


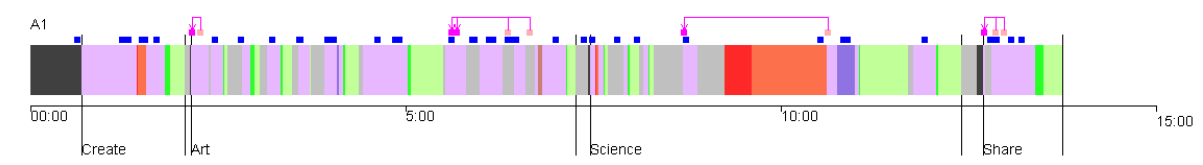

- Read Instructions

- Successful Selection

Successful Action

Non-Tooltip Selection

Tooltip Selection

- Off-Task Selection

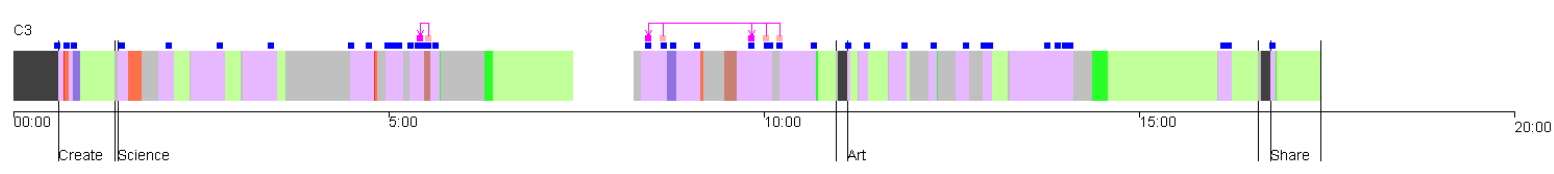

Off-Task Action

- Skim

$\checkmark$ Retry

- Selection

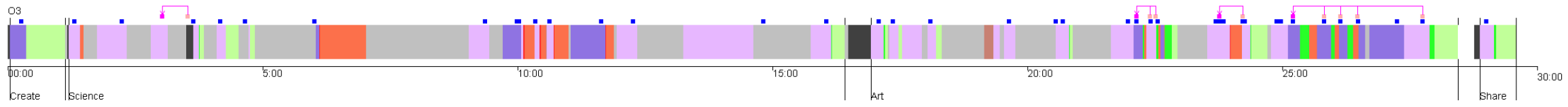

Figure 4.3: Example of three timelines, one from each age group: A1 (top), C3 (middle), and O3 (bottom), where $\mathrm{Ax}, \mathrm{Cx}$, and Ox refer to participant IDs. The timelines show the occurrence and duration of the events for the four main tasks. They show, for example, that O3 has longer duration of skim events (grey bars) than A1 and C3. 


\subsection{Interview}

We analyzed the interview transcripts in multiple sessions, where members of the team discussed key themes that could further explain the behaviors indicated by the logged events. The recurring themes highlighted in children, adults, and older adults responses were related to their overall experience of using OneNote, the specific challenges that they faced and their strategies for solving those challenges during exploration.

\subsection{Questionnaire}

We concluded our data analysis by looking at the responses from the three questionnaires filled out by each participant related to their computer and application expertise as well as their before and after self-efficacy ratings. We performed the Kruskal-Wallis $\mathrm{H}$ test on the expertise questionnaire along with post-hoc comparisons and a combination of the Wilcoxon signed-rank test and the Kruskal-Wallis $\mathrm{H}$ test on the self-efficacy questionnaires. 


\section{Chapter 5}

\section{Results}

Before moving on to our primary results, we describe our participant's expertise as analyzed from the demographic data. We then present our main results by first providing an overview of children's, adults', and older adults' performance of using OneNote for the first time. Next, we look at their interface exploration and unpack the differences in: (1) how the participants in different age groups determine, locate and select relevant features within the application and (2) how they deal with performance breakdowns and evaluate the usefulness of their performed actions. Finally, we touch on their overall feeling after using OneNote and their general help-seeking preferences. In addition to the different age groups, we considered gender as an independent variable but found no significant difference in our results (recall that we recruited an equal number of male and female participants in each age category). Hence, to simplify, we focus on age-related differences. 


\subsection{Participants' Expertise and Overall Per- formance}

In this section, we describe the differences in our participants' expertise with various devices and applications, and then we give an overview of their overall performance times when using Microsoft OneNote for the first time.

\subsubsection{Adults have the most experience with different applications, children's and older adults' current software use is similar}

We ran the Kruskal-Wallis H test on the expertise questionnaire data (Figure 5.1). Participants could rate their years of experience per device from 'Less that 1 year' to ' 11 years and above' and their frequency of use per application from 'Never' to 'Daily.' We found that there was a significant difference in means between the age groups when it came to their number of years of experience with desktops $(H=14.561, p<.001)$, laptops $(H=10.292, p<.006)$, and smartphones $(H=8.810, p<.012)$. A post-hoc test to check pairwise comparisons showed that children had significantly fewer years of desktop experience than adults $(p=.004)$ and older adults $(p=.002)$ whereas adults' and older adults' years of desktop experience was not significantly different. However, when it came to the years of laptop and smartphone experience, adults had significantly more experience than both children and older adults ( $p=.011$ and $p=.024$ for laptops, $p=.048$ and $p=.019$ for smartphones) whereas children's and older adults' years of laptop and smartphone experience was not different. 


\begin{tabular}{llll} 
& Children & Adults & $\begin{array}{l}\text { Older } \\
\text { Adults }\end{array}$ \\
\hline \multicolumn{4}{c}{ Years of Experience } \\
\hline Desktop* Device \\
Laptop* & $3-4$ & $8-10$ & $8-10$ \\
Tablet & $1-2$ & $8-10$ & $1-2$ \\
Smartphone* & $3-4$ & $3-4$ & $3-4$ \\
\hline \multicolumn{4}{c}{ Frequency of Use per Application Category } \\
\hline Word Processors* & Monthly & Daily & Monthly \\
Spreadsheets* & Never & Weekly & Rarely \\
Presentation* & Rarely & Monthly & Rarely \\
Email* & Monthly & Daily & Daily \\
Other Note-Taking & Rarely & Rarely & Rarely \\
\hline
\end{tabular}

Figure 5.1: Expertise characteristics of the three age groups (median). A category with $(*)$ indicates signicant difference between age groups.

Next, we looked at participants' frequency of use for different categories of applications over the 6 months prior to taking part in the study. We found a significant difference in their current frequency of use for word processing $(H=10.191, p<.006)$, spreadsheet $(H=14.280, p<.001)$, email $(H=18.347, p<.000)$ and presentation $(H=6.975, p<.031)$ applications. Pairwise comparisons revealed that adults used word processing, spreadsheets and presentation applications significantly more often than both children and older adults $(p=.02$ and $p=.015$ for word processors, $p=.001$ and $p=.044$ for spreadsheets, $p=.001$ and $p=.002$ for presentation) whereas children's and older adults' current usage of these applications was not significantly different. Older adults only used email applications significantly more often than children $(\mathrm{p}=.001)$. Also note that 7 of our older adults were still working (4 part-time, 3 full-time) and 3 were retired.

To summarize, our adults had the most experience with technology, and although our older adults had more years of desktop experience than children, their current usage of computer applications was not very different from children. 


\subsubsection{Children are almost as fast as adults, older adults are slower}

The overall task completion times were not significantly different between children and adults, whereas older adults took a significantly longer time than the other two age groups (main effect: $F_{(2,27)}=22.1201, p<.001$ and pairwise comparisons: $p=.001$ for older adults - adults, $\mathrm{p}=.001$ for older adults - children). Children and adults completed the four main tasks with all the sub-tasks whereas 4 out of the 10 older adults gave up on at least 1 sub-task. On average, the total time to complete all four tasks (excluding the 'Read Instruction' and 'Idle' times) was 14.88 minutes for adults, 18.29 minutes for children, and 32.24 minutes for older adults. 


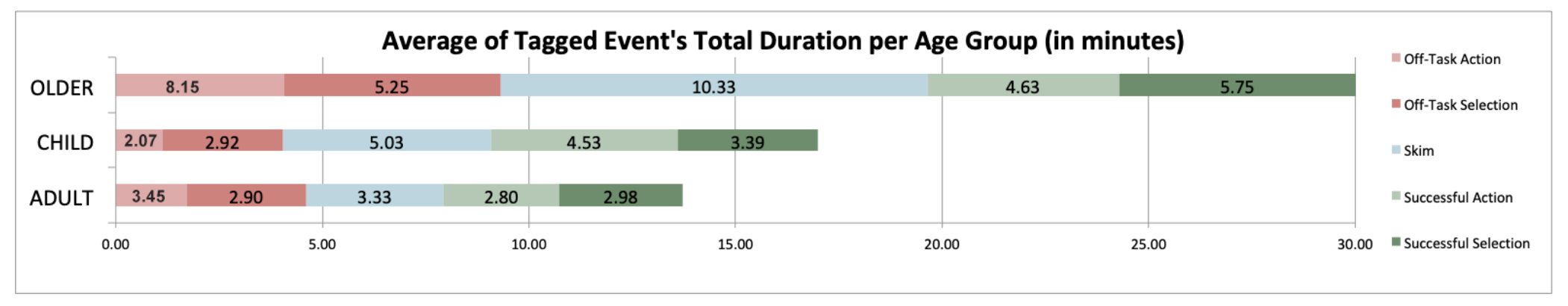

Figure 5.2: Average of the total duration per age group categorized by the five tagged events that had a duration 
The aggregated logged data clarifies which activities required the most time (Figure 5.2). It shows that children spent a bit longer than adults skimming the interface (1.5x more) and performing successful actions (1.6x more) such as drawing a flower. Surprisingly, they spent less time performing off-task actions that were not sufficient to succeed in the task, such as trying to insert a file from the computer instead of adding an online picture $(1.4 \mathrm{x}$ less).

Older adults were the slowest overall, taking $2.2 \mathrm{x}$ longer than adults and $1.8 \mathrm{x}$ longer than children. This is partly expected as prior research has shown that, in general, older adults take more time to complete movement tasks and take more pauses [40, 41]. Although Figure 5.2 shows that older adults took a longer time than children and adults in many of the categories, the biggest contributors were the time they spent performing off-task actions (2.4x slower than adults and 3.6x slower than children) and skimming the interface (3.1x slower than adults and 2.1x slower than children).

To better understand the skimming and off-task action activities, we considered both the number of occurrences and the duration per event. We found a significant main effect of the occurrence of skimming and off-task action events $\left(F_{(2,27)}=22.0034, p<0.0001\right.$ for skimming and $F_{(2,27)}=5.0963, p<$ 0.05 for off-task actions). Pairwise comparisons showed that older adults skimmed the interface and performed off-task actions significantly more often than both children ( $p=.004$ for skimming, $p=.006$ for off-task actions) and adults ( $p=.001$ for skimming, $p=.008$ for off-task actions). On average, the older adults skimmed 53.1 times and performed off-task actions 17 times during the whole study, while adults and children only skimmed 28.2 and 31.2 times respectively, and both performed off-task actions 9.2 times.

In the next section, we elaborate on how children's and (especially) the older adults' interface exploration styles resulted in their longer task completion times. 


\subsection{Interface Exploration Styles}

In this section, we describe the differences in the interface exploration styles of the three age groups in terms of how they determine, locate, and make use of relevant features for the tasks. We also discuss the effect of knowledge transfer on participants' performance.

\subsubsection{Children and older adults face different challenges in locating relevant features}

Adults were significantly quicker at making successful selections than older adults (main effect: $F_{(2,27)}=5.0797, p<0.01$ and pairwise comparisons: $p=.018)$, whereas children were in between. The average of the median duration per episode of successful selections was 4.2, 4.9, and 6.5 seconds for adults, children, and older adults respectively.

Older adults particularly struggled to locate the relevant features because they did not sufficiently investigate the features in different menus. If we consider the number of non-unique selections that were made by the three age groups, where they selected an option that they had tried before, older adults made significantly more non-unique selections than the other two age groups (main effect: $F_{(2,27)}=3.6534, p=0.04$ and pairwise comparisons: $p=.002$ for older adults - children, $p=.015$ for older adults - adults). The median percentages of non-unique selections were $55.5 \%$ for older adults compared to $43.9 \%$ and $47.5 \%$ for adults and children respectively. This is perhaps because older adults had the tendency to only select the sub-menu where they expected the feature to be, and dismissed other potential menus. For example, O8 struggled to find the 'Share' icon that was located at the top-right corner menu of the application. When asked, O8 said "I thought those things won't add value. When you write on paper you write from left to right. The headings are always on the left. I assumed the important things to be on the left side." O6 expressed a similar thought regarding where he 
expected certain features to be located: "Why are there these things [create notebook/section] at the bottom? I would expect them to be at the top, maybe under View."

Children faced different challenges when locating the relevant features. Even though their task completion times were similar to that of adults, they sometimes felt overwhelmed by the number of different menus and features. For example, C8 said "It was kind of complicated. Just like they need to make it more simple in a way. It's confusing why some options are down here [a sub-menu] and some up there [top left corner menu]." The majority of children were looking at the options at the top menu but they sometimes did not initially realize that there were more options outside 'Home'. For example, C10 said "I didn't know that if you pressed it [Insert] it would give more options inside it. Once I looked outside Home it became obvious" In addition, children particularly had difficulties locating features in the right-click (contextual) menu. The total number of right-click events was significantly lower for children (median 3 times during the whole study), than adults (10 times) and older adults (8.5 times), (main effect: $F_{(2,27)}=6.4952, p=0.0053$ and pairwise comparisons: $p=.01$ and $p=.01$ ) . Only 3 out of 10 children reported that they knew that they could right-click for more options. C8 said "I actually don't use the mouse usually so I didn't know about right-clicking." In addition, $\mathrm{C} 10$ mentioned how she discovered the right-click menu accidentally 'I meant to click on it but I pressed both [right and left click] and it [right click menu] showed up."

Adults, being more frequent users of similar software applications, made more efficient use of the different menus resulting in their quicker successful selection times. Contrary to children and older adults, the majority of the adults found the features easy to locate. For example, A4 said "I think they [the features] were relatively simple to discover. There were obvious features like the Draw menu. You probably saw me right-clicking several times. If it didn't have what I was looking for then I would look somewhere else." Similar 
to A4, A6 also mentioned how he would just explore another sub-menu if he could not find the feature where he expected it to be. "I would firstly go to the menu that looks most relevant and scan from left to right. If this is not the right one, go to the next toolbar." Therefore, overall, adults often found the relevant features because they were comfortable exploring and knowledgeable about different menus, including the right-click menu.

\subsubsection{Older adults struggle more than children and adults to determine the relevant sequence of se- lections}

Older adults missed selecting a significantly higher number of correct features than children and adults, despite being on the right sub-menu (main effect: $F_{(2,27)}=3.5099, p=0.04$ and pairwise comparisons: $p=.004$ for older adults - children, $p=.012$ for older adults - adults). The median number of missed features was 15.5 for older adults, 9 for children and 7.5 for adults. This indicates that even though older adults were sometimes on the right track, they got confused about the features that were relevant to complete the task. For example, during the Science task, O6 had already determined the relevant sequence of selections and opened the 'Insert' menu but missed to click on the 'Researcher' feature which was the second last option from the right. In the semi-structured interview, he explained that he thought that the feature would be something like a 'magnifying glass symbol' under the 'Insert' menu. Similarly, there was O10 who had 32 instances of missed features, the highest among all the participants. When asked about why she missed some of the features she said "Maybe I am too used to looking on my left-hand side than look at my right-hand side to search for the commands. If I got used to it I think I would try to look at both sides."

Furthermore, some older adults tried to determine the selection sequence by searching for words similar to the task instructions on the interface. For 
example, O2 mentioned "I didn't have any plan on how to approach it. I would just rely on the instruction page and then go to see if I can find a similar term. It all depends on the information available here [the task list] and here [the interface]." This approach did not always work for them as the task list would not have keywords that could directly be mapped to the feature set.

Aside from missing the relevant features, older adults also performed off-task selections more often than adults and children (Figure 5.3), a statistically significant difference for the Science task (main effect: $F_{(2,27)}=$ $4.8991, p=.002$ and pairwise comparisons: $p=.001$ for older adults - adults, $p=.002$ for older adults - children). This could be because the sub-tasks under Science were more challenging as the participants had to make the connection between the feature 'Researcher' under 'Insert' menu to 'inserting information about polar bears' and the 'Password Protect' feature under a right-click menu to 'locking the Science section with a password'.

When we further looked at the nature of the off-task selections made by the older adults in the Science task, we found that older adults had a significantly higher number of cycles, than the other two age groups (main effect: $F_{(2,27)}=5.9271, p<.001$ and pairwise comparison: $p=.01$ for older adults - children, $p=.04$ for older adults - adults). 7 out of the 10 older adults had at least one cycle where they repeated the same sequence of off-task selections or a retry of the same feature, both of which sometimes lead them to perform off-task actions. Figure 5.4 shows the deviation from the shortest path to complete a sub-task under Science by O7 and O4. O7 eventually did complete the sub-task whereas $\mathrm{O} 7$ gave up in the end without finding the 'Researcher' feature. The struggle to determine the relevant sequence selection sometimes caused frustration among older adults where they required a hint to proceed in the right direction. 


\begin{tabular}{|c|c|c|c|c|c|c|c|c|c|c|c|c|}
\hline \multirow[t]{2}{*}{ Age Group } & \multicolumn{3}{|c|}{ Create Notebook Task } & \multicolumn{3}{|c|}{ Art Task } & \multicolumn{3}{|c|}{ Science Task } & \multicolumn{3}{|c|}{ Share Notebook Task } \\
\hline & $\begin{array}{l}\text { Minimum } \\
\text { Selections }\end{array}$ & $\begin{array}{l}\text { Successful } \\
\text { Selections }\end{array}$ & $\begin{array}{l}\text { Off-Task } \\
\text { Selections }\end{array}$ & $\begin{array}{l}\text { Minimum } \\
\text { Selections }\end{array}$ & $\begin{array}{l}\text { Successful } \\
\text { Selections }\end{array}$ & $\begin{array}{l}\text { Off-Task } \\
\text { Selections }\end{array}$ & $\begin{array}{l}\text { Minimum } \\
\text { Selections }\end{array}$ & $\begin{array}{l}\text { Successful } \\
\text { Selections }\end{array}$ & $\begin{array}{l}\text { Off-Task } \\
\text { Selections }\end{array}$ & $\begin{array}{l}\text { Minimum } \\
\text { Selections }\end{array}$ & $\begin{array}{l}\text { Successful } \\
\text { Selections }\end{array}$ & $\begin{array}{l}\text { Off-Task } \\
\text { Selections }\end{array}$ \\
\hline Children & 1 & 1.1 & 2.7 & 14 & 18 & 12.7 & 8 & 9.4 & 9.4 & 1 & 1 & 5.5 \\
\hline Adults & & 1.1 & 4.5 & & 19.8 & 11.7 & & 8.5 & 11.9 & & 1.1 & 4.7 \\
\hline Older Adults & & 1.1 & 5 & & 21.3 & 11.4 & & 10.9 & 21.6 & & 1.1 & 5.8 \\
\hline
\end{tabular}

Figure 5.3: Median number of selections by age group for each of the four tasks as well as the minimum number of selections required for each. Older adults performed more off-task selections during 'Science Task.' 


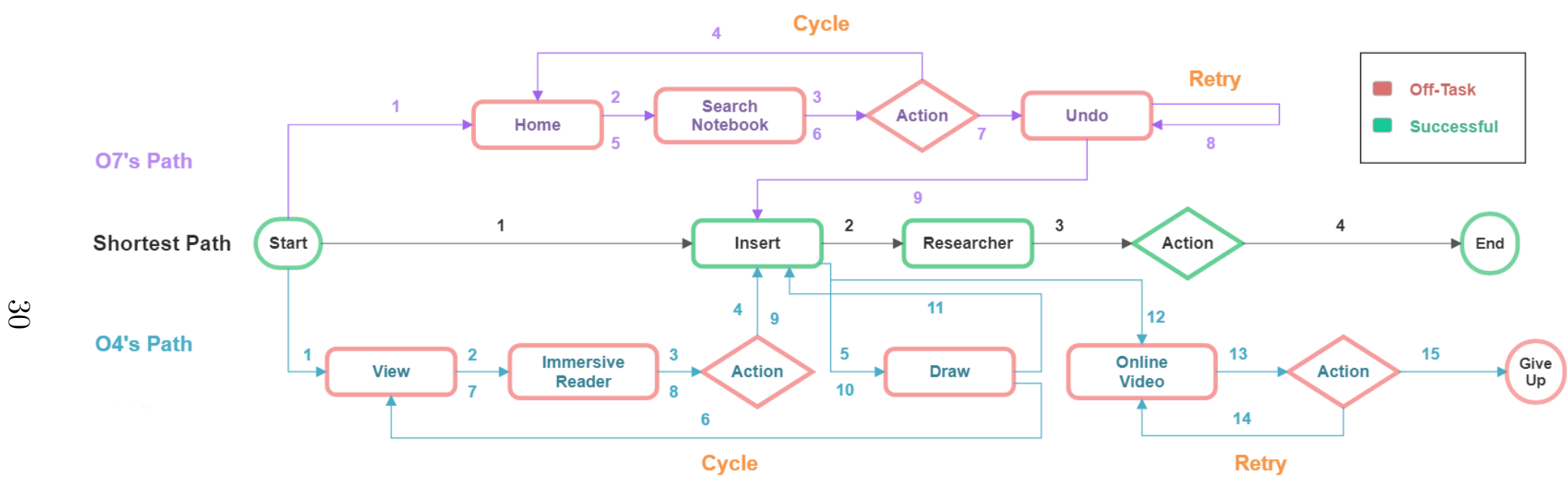

Figure 5.4: Example of the paths taken by O7 and O4 during a Science sub-task. Each of them deviated from the shortest path and had off-task selection cycles and retries. O7 eventually got on the right path and completed the sub-task whereas $\mathrm{O} 4$ gave up. 


\subsubsection{Adults and older adults rely on past software experience, children rely on real-life experience}

The adult participants reported that they often guessed the relevant features based on their past experience with similar software, e.g., Microsoft Office, to determine the possible menus and features. For example, talking about her discovery of relevant features, A8 said "It's pretty similar to Word. There are more different tools to explore here. I don't know if Word has the option to share notes but it's pretty cool. I did a lot of inference from my prior knowledge to guess and check." This suggests positive knowledge transfer.

Although rarely occurring, we also observed a negative knowledge transfer for adults, when a participant made a wrong assumption based on their knowledge of previous software. For example, A2 had gone to the 'Home' menu to create a new notebook mentioning that he thought he should go to the menu similar to the 'File' menu of Microsoft Word to create a new file. This may potentially hinder efficient exploration if the user incorrectly narrows down the scope of exploration.

Similar to the adults, the older adults were also affected by their past experience of using similar applications but for them, negative transfer learning seemed to dominate. For example, when 09 had to add the current date to his notebook, instead of simply typing it in he was looking for a function called 'Date' as Microsoft Word would have it. He said "It doesn't seem logical that I can't press on some function to insert a date like in Word." O1 also expressed similar views regarding her confusion when she tried to relate OneNote with Microsoft Word: "I was not too sure how to go back Home. It seems a little bit different from what I mostly work on. I mostly work on Word and whenever I am not too sure I will just go back to Home, this [OneNote] doesn't seem to work like that. It has to depend on my luck."

In contrast, children seemed to rely more on their real-life experiences as they had less computer experience, which often had a positive effect on their exploration. For example, explaining how he found the 'Researcher' option, 
$\mathrm{C} 2$ mentioned "When the teacher gives you homework to do and you dont know much about it, she says you do research. So I thought Researcher was something that could research for you." Similar to C2, C1 also expressed how he mapped the features to real-life examples "Like, if you look at the Ruler option, I think about the ruler straight away. You can measure. Math means you can do plus, minus, division."

\subsubsection{Tooltips can be helpful but are infrequently used by the three age groups}

One way for the application to communicate what a feature does is through the tooltip. All three age groups made significantly more number of selections without first reading the tooltip. On average, only $9.2 \%, 15.8 \%$, and $21.7 \%$ (for adults, children, and older adults respectively) of the total selections for each age group were tooltip selections. This is particularly surprising in the case of older adults because they had spent significantly more time skimming the interface, and yet they did not leverage the tooltip that often. This indicates that even when older adults were skimming they were just looking around for features that might help them to proceed.

Next, if we look at the nature of the tooltip selections that were made by each age group, older adults made significantly more successful selections than adults (main effect: $F_{(2,27)}=5.0797, p<.01$ and pairwise comparisons: $p=.03)$ when they did read the tooltip, whereas children were in between. A median of $14.6 \%$ of the successful selections made by older adults were tooltip selections, compared to $10.3 \%$ for children and only $4 \%$ for adults. This may suggest that tooltips were more impactful for older adults to help them map the icon and terminology associated with a feature to its function, and they might have struggled less to determine the relevant features if, during skimming, they had made more use of the tooltip. 


\subsection{Facing Breakdowns}

In this section, we discuss the hurdles that participants faced during exploration and the strategies that they used to overcome those.

\subsubsection{Children are quick at recovering from breakdowns, older adults take time}

Children had the shortest average total duration of off-task actions, only 1.1 minutes, compared to 1.7 and 4.1 minutes for adults and older adults (Figure 5.2). This suggests that children were able to understand the system feedback and address the outcome of their actions. Even when they made an off-task selection, they were quick to detect it and move on to another option. For example, in the Art task, a lot of participants did not realize right away that they had to activate the drawing mode by clicking a 'Hand' icon first before drawing. Talking about her experience of being able to quickly recover from an off-task action, such as trying to drag the pen tool icon to draw which was not a supported interaction, C3 said "I was dragging it [pen] as I was really trying to draw. Then I looked again and saw the hand and hovered over that to see what it did."

Similar to children, adults were also relatively good at understanding the feedback from the system to determine whether things worked as they expected or not. Some adults also went through the breakdown of not clicking on the 'Hand' icon and only selecting a pen. However, they were also able to quickly realize that they had to find a workaround. A2 mentioned, "... because it wasn't working, this is like the obvious [Hand] icon, like the finger, just that icon is very readable."

Older adults, on the other hand, spent a significantly longer time carrying out various off-task actions than children and adults (main effect: $F_{(2,27)}=$ 9.1356, $p<.01$ and pairwise comparisons: $p=.04, p=.04)$ and were also

significantly more unsure of their actions (main effect: $F_{(2,27)}=9.5846, p<$ 
.01 and pairwise comparisons: $p=.002, p=.003$ for older adults - children and older adults - adults). Reflecting on his experience with the drawing sub-task, O3 mentioned how he did not know he had to select both the pen tool and the 'Hand' icon: "When you asked me to draw, I thought it was challenging, I couldn't think of the fact that I had to choose a color [pen]. If you weren't here [to give a hint] I would either have to go to the web or call somebody to ask." In addition, many of our older adults had difficulties understanding system feedback. For example, some selections trigger interface changes such as a pop-up menu or a mode-switch (e.g., clicking on the 'Hand' icon only activates the drawing mode), rather than a change to the data. Older adults often did not realize this difference, and tended to use the 'Undo' button hoping to undo a selection's impact on the interface. For example, in Figure 5.4, O7 is seen selecting 'Undo' hoping to undo the effect of the 'Search Notebook' selection that had impacted the interface by opening up a pop-up menu but she did not understand that she was removing her content instead. O2, O4, O6, O9 and $\mathrm{O} 10$ also faced this breakdown where they were unable to understand the outcome of selecting the 'Undo' button and accidentally removed their data.

\subsubsection{Children rely on reading when facing a break- down, older adults try out random options}

Children were careful in making selections and did not want to do something wrong. Their fear of trying out wrong options could possibly be due to past experiences, such as $\mathrm{C} 10$ who mentioned "I have used the Word document before, I accidentally highlighted the text. Then deleted it. I tried to solve it myself first and then I was at school, so I asked my friends and then the teacher." When facing a breakdown such as not being able to locate the correct feature or being stuck with an off-task action, 7 out of 10 children said that relied on the text labels to make an educated guess about the correct feature. Referring to how text supported him during breakdowns, C8 
said "Well, I would just kind of go into 'Insert', 'Draw', 'Home', 'View' and read the options. Then work off from there." Figure 3.1 (a) and (b) further show an example of $\mathrm{C} 2$, who opened the 'Insert' menu and scanned the text labels systematically, as indicated by her eye-gaze, before moving the cursor to making a selection. Besides reading the text label, 2 out of the 10 children mentioned that they found the tooltip to be useful such as C10 who stated "When I was in Home, I didn't know what they meant so I would go to the option and then stay on it. Then I could read what it was."

Adults and older adults, on the other hand, resorted to trial \& error when they got stuck. However, for older adults, this approach was less effective as they would often click on random features just to see if they would work once their initial sequence of actions was unsuccessful. Overall, 8 out of 10 older adults mentioned trial \& error. For example, talking about her approach to deal with breakdowns $\mathrm{O} 8$ said "Because I often couldn't find a logical sequence, I was clicking on everything one after the other to see if something fit." Similar to O8, O5 expressed "It was more hit and miss. It wasn't that straightforward. I was trying out things many times to see if it works." This further explains why older adults had a significantly higher number of off-task selections and cycles as previously discussed.

Although adults also adopted the trial \& error approach when they faced a breakdown, they seemed to have better deduction strategies instead of selecting options in a random manner. For example, A6 said "I think my approach is read, try it, click around. I would firstly go to the menu that looks most relevant. Mostly just try it. If this is not the right one, go to the next toolbar. It won't be a big deal to click on a wrong button." A3, A4, A5 and A9 also expressed similar ideas. A9 described her approach as "Reading, seeing, trying. I wouldn't just choose random ones. I went with the first one that made sense if that did not work, I will look for another one." Therefore, it suggests that even when adults were doing trial \& error, they were doing it in a targeted manner. 


\subsection{Overall Feeling and Help-Seeking Approach}

In this section, we describe the overall feeling of the participants after exploring OneNote for the first time. We also touch on the differences in their preferred help-seeking approach.

\subsubsection{Children and adults seem fairly content with self- exploration, older adults feel disappointment}

To understand how the three age groups felt about using a new application and if it affected their confidence levels, we analyzed their self-efficacy questionnaires before and after the tasks were performed. Although the withingroup analysis showed no significant change in the confidence levels within each group before and after they had used OneNote, our between-group analysis revealed another story.

Older adults started the tasks with significantly lower confidence levels than adults $(p=.035)$ and children $(p=.039)$, and even after interacting with OneNote, their confidence levels stayed significantly lower $(p=.008$ for older adults - adults and $p=.042$ for older adults - children). This indicates that for older adults, their experience of using OneNote did not improve their initial low confidence levels. If anything, it caused frustrations, as O7 mentioned "It's a headache. You shouldn't have to touch this touch that. It's too much of clicking here and clicking there. If I want to do something quickly I don't want to click so much. I just wouldn't use it." Similarly, O1, O2, O8, O9, and O10 also reported that they felt unhappy with their experience. O3 further mentioned that he had expected the interface to be more intuitive "It wasn't as intuitive and as easy as I thought it would be. I guess with any new application I need practice to get used to it."

In contrast, children and adults maintained a high confidence level both before and after they had used OneNote. It seems that adults had expected OneNote to be more complicated, like some of the other applications they 
had used in the past. For example, A5 mentioned "It's simple and I guess the design, the way it looked, it's not as complicated as I thought. I expected something like, you know, Microsoft Excel." Overall, 9 out of 10 adult participants expressed similar views of finding OneNote easy to use, with the exception of A2 who found it difficult: "I found it a bit hard to use. It's not intuitive at all. Like there are some conventions where you would expect the options to be and I don't see them there."

Similar to adults, children also expressed satisfaction with their experi-

ence of using OneNote, although they mentioned that the interface could be further simplified. Such as C1 who said "I am happy but what I dislike is there is all this [sub menu options]. Then you have these [main menu options]. You don't know where what is." In addition, C10 mentioned how he understood the interface better as he progressed in the tasks: "For this one [Science], it was a bit difficult. But when I did Art I got used to it."

\subsubsection{Adults prefer Google search, children and older adults prefer instructions from people or the built- in help}

In the study, we restricted the participants' help-seeking methods to built-in help. However, 7 out of 10 adults mentioned in the semi-structured interview that they would rather use a search engine (e.g., Google Search) or video tutorials (e.g., YouTube) if allowed. A6 and A7 also considered asking someone if they thought the task was too technical.

Children had mixed responses when it came to their help-seeking preference. From the interview responses, we found that most of them (6 out of 10) preferred to solve the problem on their own first, and then ask a parent, a teacher or even google home for help afterward. For example, C6 said "Usually, I would try and figure it out more on my own. Sometimes I would search it up on the internet or ask my Dad." 
Older adults had a preference for using the built-in help. 5 out of 10 older adult participants mentioned the built-in help but only 2 of them had successfully used it during the tasks. It is interesting to note that 3 out of the 5 older adults who mentioned built-in help did not realize that it was available in OneNote. Talking about his preferred help-seeking method O6 said "Help button, which I did not see here. I would usually definitely use that." In addition to using the built-in help, O3 mentioned other help resources that he would use: "So yes, if there is a built-in help typically I would try to use that. If there isn't I would go to the web. Or if there are people around me that have used the application, if someone is in the next room, I will open the door to ask them."

The insights from the interview responses are further confirmed if we also look at the self-efficacy questionnaire responses for the help-seeking approach that participants felt the most confident with. The median ratings of adults were the highest for google search (9 on a scale of 10) and the lowest for the condition where they had not used any similar application before (5.75). For children and older adults, their median ratings were the highest for having someone show them how to do the tasks (9.5 and 7 respectively) and the lowest was if there was no one around for help (5.75 and 3.5 respectively). 


\section{Chapter 6}

\section{Discussion and Implications for Design}

We reflect on our key findings and discuss their implications to foster efficient exploration for children, adults and older adults. Where possible, we provide specific implications for design.

We were surprised to see that children performed almost as well as the adults when using the feature-rich application, Microsoft OneNote, for the first time. Prior work on children's use of problem-solving software had indicated that children tend to feel lost in different parts of an application and tend to try out many different actions to get ahead [25, 19]. Yet, we saw that even when children were exploring the application, they seemed careful to avoid making mistakes. They often read the text labels and sometimes the tooltips for guidance. Even when they had a breakdown, i.e. carrying out off-task actions, they were quick to detect it and recover. In contrast, older adults fell into the active user paradox [4] where they resorted to less systematic trial \& error strategies without relying on the tooltip, once their initial sequence of actions had failed. This confirms prior work on older adults being more negatively affected by errors $[15,16,17]$, which then impacts their initial exploration strategy and causes them to struggle. 
While it is not surprising that older adults had slower task completion times - there are natural declines in cognitive and motor abilities due to aging [49], as well as documented fears of exploring a new application [15] our study further revealed additional factors that contributed to their longer task completion times. Older adults had multiple selection cycles and retries during exploration where they deviated from the shortest path and selected the same sequence of irrelevant features, that often led them to perform unnecessary actions and consequently slowed them down (Figure 5.4). Adults and children, on the other hand, had significantly fewer such cycles in their interaction data, instead moving on to trying out different sets of options. This could be an indication of short-term memory loss where older adults forget the sequence of actions that they have carried out or where they do remember but are simply unsure of whether they have performed the actions correctly [42].

Implication for Design: Detect selection cycles and offer support. The system could detect cycles and retries in users' selections and offer support. A simple possibility would be to suggest the use of built-in help as some of our older adults did not notice that there was a built-in help option. In addition, based on the user's interaction, the system could invoke a heatmap showing the recent cycles and retries of selected options, similar to Patina [50], and encourage the users to better understand the use of those features by using the tooltip. Moreover, seeing a visual representation of their repeated selections could motivate users to reflect on their previous actions and prevent them from repeating the wrong path.

Another surprising finding was that the impact of knowledge transfer on exploration style was different for children, adults, and older adults. Adults were the most experienced with recent technologies, which generally seemed to help them perform well. Although our older adults reported comparable past experience with similar applications, they had not used these regularly in the past six months. This might have caused a mismatch in their mental 
models for how they expected the application to behave and the way that it is designed today. Hence, although they spent a long time skimming the interface, they were making more non-unique selections. This is consistent with O'Brien's work on understanding the effect of older adults' prior knowledge on interactions with technology in general [37], where our observational study provides additional insights on how having past knowledge of similar applications more specifically does not necessarily make self exploration efficient. Children, on the other hand, had used fewer computer applications than our older adults but were still as confident as our adults. They were most familiar with using tablets that offer relatively simpler applications than desktop computers. Their lack of experience with personal computers and pointing devices (e.g., a mouse) may hinder their discovery of interactions such as the right-click menu, which has the metaphor of right-clicking a mouse, something more foreign to them.

Implication for Design: Support feature discovery and skimming by appropriately revealing signifiers for hidden menus, including drop-downs and the right-click menu. The interface could detect the user's eye-gaze on the screen together with skimming behaviour and then subtly provide signifiers. For example, the interface could highlight a 'Reveal' button similar to ExposeHK [51], which the user could click on to discover hidden menus. These signifiers could be ignored or acted upon, without unnecessarily cluttering the interface for all users. In addition, this might inspire users to explore the menu regions they had not previously paid attention to.

Lastly, it was also surprising for us to find that older adults particularly struggled to understand the scope of the 'Undo' mechanism that is universally used today. They often tried to use 'Undo' hoping to undo a selection that had impacted the interface, whereas the current 'Undo' mechanism only acts on selections that involve operations on data. Hence, some of the older adults ended up selecting 'Undo' incorrectly and accidentally removing important content. 
Implication for Design: Provide feedback of user actions for both changes to the data/content and to the interface, and enable users to undo either type of action. Although recent work has widely explored 'Selective Undo', where users can undo specific operations instead of backtracking in a linear manner $[52,53]$, we recommend expanding the 'Undo' scope by distinguishing between undoing an operation that affects the data/content or merely undoing a selection. For example, the system could offer a feature such as 'My Past Actions' that could show the user a list of the features that they had selected along with whether a feature caused a change to their data/content or just to the interface. The user could then hover on the list item to undo the effect of certain selections.

We envision these design recommendations to be particularly useful for both children and older adults. At the same time, they would not get in the way of adults who do not need the extra assistance, as the support would be triggered based on the user's interactions. The adults in our study did not seem to struggle very much. We do not interpret this as inconsistent with prior work, but rather complementary - OneNote with approximately 90 features is not likely as feature-rich as applications such as Photoshop that has over 200 features ${ }^{1}$, with which adults have been shown to have difficulty $[20,54]$. In addition, the nature of our tasks might not have been as complex for the adults as those studied before.

\footnotetext{
${ }^{1}$ We provide an approximation of the number of features by counting the different menus and the options in each of them.
} 


\section{Chapter 7}

\section{Threats to Validity}

In this chapter we acknowledge the limitations of our work by discussing the threats to internal, construct, and external validity.

\subsection{Internal Validity}

In our study, we did not control for expertise which could have resulted in some of the differences that we saw in participants' overall performance with OneNote. It is possible that older adults who have used various applications more recently than the older adults who took part in our study, may have struggled less. In addition, we recruited all of our children from one school where they may have been intellectually compatible with one another, more so than had they been recruited from different schools.

\subsection{Construct Validity}

There is no universally accepted definition of exploration. Although we spent a significant amount of time iterating over the codebook and finalizing the list of exploration events, other researchers may be able to look at the videos with a different perspective and be able to identify codes that we may have 
missed. The same applies for the interview transcripts where there may be additional themes regarding participants' experience of using OneNote for the first time.

\subsection{External Validity}

We investigated participants' performance with only one type of application, Microsoft OneNote, which may not have been equally complex for all three age groups. We also looked at their exploration styles with a list of tasks which may have influenced the way in which they navigated the interface. Furthermore, we restricted the participants from taking external help and made them focus on self-exploration whereas outside the study, it is likely that participants would use a combination of help resources and self-exploration to learn a new application. 


\section{Chapter 8}

\section{Conclusion and Future Work}

When learning a feature-rich application for the first time, users often explore different menus and features to accomplish their desired tasks. Today, these applications are being used by children, adults and older adults alike. Our study contributes insights into the interface exploration styles of the three age groups, the challenges that they face and the strategies that they use to deal with breakdowns. We found, among other things, that children explore the interface carefully but struggle to locate contextual menus (because of lack of mouse exposure), whereas older adults have difficulties determining relevant sequence of features and repeat failed selections.

In terms of the study procedure and its threats to validity as discussed in the previous chapter, future work could expand the choice of application with various degrees of complexity, beyond productivity, and investigate the effectiveness of the design implications with a broader sample size. In addition, future work could consider supporting other means of help-seeking along with a task-free approach and inspect any additional events that could further characterize participants' exploration styles.

Nevertheless, our work is an important step towards understanding the diversity in users' approaches to learning through exploration. An extension of this would be to create working prototypes that stem from our implica- 
tions for design and evaluate them with the three age groups. It would be interesting to see how well the automatic detection of cycles and skimming behaviours could help older adults proceed in the right direction and curtail their frustrations. In addition, there is scope for future work to explore ways in which children could be familiarized with contextual menus. Although we discuss the possibility of revealing signifiers for hidden menus, future work could further investigate different approaches to support prior interactions that children are already familiar with as they shift from using a tablet to a computer. With a better understanding of the differences in children, adults, and older adults' interface exploration styles, we hope to inspire work that aims to accommodate diverse users through design and improve software learnability across age groups. 


\section{Bibliography}

[1] I. His and C. Potts, "Studying the evolution and enhancement of software features," in Proceedings of the International Conference on Software Maintenance (ICSM'00), ser. ICSM '00. Washington, DC, USA: IEEE Computer Society, 2000, pp. 143-. [Online]. Available: http://dl.acm.org/citation.cfm?id=850948.853409

[2] L. Kaufman and B. Weed, "Too much of a good thing?: Identifying and resolving bloat in the user interface," SIGCHI Bull., vol. 30, no. 4, pp. 46-47, Oct. 1998. [Online]. Available: http://doi.acm.org/10.1145/310307.310370

[3] J. McGrenere and G. Moore, "Are we all in the same "bloat"?" in Proceedings of the Graphics Interface 2000 Conference, May 15-17, 2000, Montr'eal, Qu'ebec, Canada, May 2000, pp. 187-196. [Online]. Available: http://graphicsinterface.org/wp-content/uploads/gi2000-25.pdf

[4] J. M. Carroll and C. Carrithers, "Training wheels in a user interface," Commun. ACM, vol. 27, no. 8, pp. 800-806, Aug. 1984. [Online]. Available: http://doi.acm.org/10.1145/358198.358218

[5] D. G. Novick, O. D. Andrade, and N. Bean, "The micro-structure of use of help," in Proceedings of the 27th ACM International Conference on Design of Communication, ser. SIGDOC '09. New 
York, NY, USA: ACM, 2009, pp. 97-104. [Online]. Available: http://doi.acm.org/10.1145/1621995.1622014

[6] T. Grossman, G. Fitzmaurice, and R. Attar, "A survey of software learnability: Metrics, methodologies and guidelines," in Proceedings of the SIGCHI Conference on Human Factors in Computing Systems, ser. CHI '09. New York, NY, USA: ACM, 2009, pp. 649-658. [Online]. Available: http://doi.acm.org/10.1145/1518701.1518803

[7] D. A. Norman and S. W. Draper, User Centered System Design; New Perspectives on Human-Computer Interaction. Hillsdale, NJ, USA: L. Erlbaum Associates Inc., 1986.

[8] J. M. Carroll and M. B. Rosson, "The paradox of the active user," in Interfacing Thought: Cognitive Aspects of Human-computer Interaction, J. M. Carroll, Ed. Cambridge, MA, USA: MIT Press, 1987, pp. 80-111. [Online]. Available: http://dl.acm.org/citation.cfm?id=28446.28451

[9] J. Rieman, "A field study of exploratory learning strategies," $A C M$ Trans. Comput.-Hum. Interact., vol. 3, no. 3, pp. 189-218, Sep. 1996. [Online]. Available: http://doi.acm.org/10.1145/234526.234527

[10] K. McKnight, K. O'Malley, R. Ruzic, M. K. Horsley, J. J. Franey, and K. Bassett, "Teaching in a digital age: How educators use technology to improve student learning," Journal of Research on Technology in Education, vol. 48, no. 3, pp. 194-211, 2016. [Online]. Available: https://doi.org/10.1080/15391523.2016.1175856

[11] L. Vermette, J. McGrenere, C. Birge, A. Kelly, and P. K. Chilana, "Freedom to personalize my digital classroom: Understanding teachers' practices and motivations," in Proceedings of the 2019 CHI Conference on Human Factors in Computing Systems, ser. CHI '19. New York, NY, USA: ACM, 2019, pp. 318:1-318:14. [Online]. Available: http://doi.acm.org/10.1145/3290605.3300548 
[12] R. Sewdas, A. de Wind, L. G. van der Zwaan, W. E. van der Borg, R. Steenbeek, A. J. van der Beek, and C. R. L. Boot, "Why older workers work beyond the retirement age: a qualitative study," in BMC Public Health, 2016.

[13] Y. Barnard, M. D. Bradley, F. Hodgson, and A. D. Lloyd, "Learning to use new technologies by older adults: Perceived difficulties, experimentation behaviour and usability," Computers in Human Behavior, vol. 29, no. 4, pp. 1715 - 1724, 2013. [Online]. Available: http://www.sciencedirect.com/science/article/pii/S0747563213000721

[14] S. L. Gatto and S. H. Tak, "Computer, internet, and e-mail use among older adults: Benefits and barriers," Educational Gerontology, vol. 34, no. 9, pp. 800-811, 2008. [Online]. Available: https://doi.org/10.1080/03601270802243697

[15] J. Chin and W.-T. Fu, "Age differences in exploratory learning from a health information website," in Proceedings of the SIGCHI Conference on Human Factors in Computing Systems, ser. CHI '12. New York, NY, USA: ACM, 2012, pp. 3031-3040. [Online]. Available: http://doi.acm.org/10.1145/2207676.2208715

[16] R. Leung, C. Tang, S. Haddad, J. Mcgrenere, P. Graf, and V. Ingriany, "How older adults learn to use mobile devices: Survey and field investigations," ACM Trans. Access. Comput., vol. 4, no. 3, pp. 11:1-11:33, Dec. 2012. [Online]. Available: http://doi.acm.org/10.1145/2399193.2399195

[17] N. Wagner, K. Hassanein, and M. Head, "Review: Computer use by older adults: A multi-disciplinary review," Comput. Hum. Behav., vol. 26, no. 5, pp. 870-882, Sep. 2010. [Online]. Available: http://dx.doi.org/10.1016/j.chb.2010.03.029 
[18] M. Kähkönen and S. Ovaska, "Initial observations on children and online instructions," in Proceedings of the 2006 Conference on Interaction Design and Children, ser. IDC '06. New York, NY, USA: ACM, 2006, pp. 93-96. [Online]. Available: http://doi.acm.org/10.1145/1139073.1139098

[19] B. Chimbo, J. H. Gelderblom, and M. R. de Villiers, "A comparative analysis of the meaning of 'learnability' for child and adult users," 2011.

[20] K. Kiani, G. Cui, A. Bunt, J. McGrenere, and P. K. Chilana, "Beyond "one-size-fits-all": Understanding the diversity in how software newcomers discover and make use of help resources," in Proceedings of the 2019 CHI Conference on Human Factors in Computing Systems, ser. CHI '19. New York, NY, USA: ACM, 2019, pp. 340:1-340:14. [Online]. Available: http://doi.acm.org/10.1145/3290605.3300570

[21] S. de Mul and H. van Oostendorp, "Learning user interfaces by exploration," Acta Psychologica, vol. 91, no. 3, pp. $325-344, \quad 1996$, usage of Modern Technology by Experts and Non-professionals. [Online]. Available: http://www.sciencedirect.com/science/article/pii/0001691895000607

[22] B. Lafreniere, A. Bunt, and M. Terry, "Task-centric interfaces for feature-rich software," in Proceedings of the 26th Australian ComputerHuman Interaction Conference on Designing Futures: The Future of Design, ser. OzCHI '14. New York, NY, USA: ACM, 2014, pp. 49-58. [Online]. Available: http://doi.acm.org/10.1145/2686612.2686620

[23] C.-I. Trudel and S. J. Payne, "Reflection and goal management in exploratory learning," International Journal of Human-Computer Studies, vol. 42, no. 3, pp. 307 - 339, 1995. [Online]. Available: http://www.sciencedirect.com/science/article/pii/S1071581985710154 
[24] L. J. Couse and D. W. Chen, "A tablet computer for young children? exploring its viability for early childhood education," Journal of Research on Technology in Education, vol. 43, no. 1, pp. 75-96, 2010. [Online]. Available: https://doi.org/10.1080/15391523.2010.10782562

[25] N. Hudson, B. Lafreniere, P. K. Chilana, and T. Grossman, "Investigating how online help and learning resources support children's use of 3d design software," in Proceedings of the 2018 CHI Conference on Human Factors in Computing Systems, ser. CHI '18. New York, NY, USA: ACM, 2018, pp. 257:1-257:14. [Online]. Available: http://doi.acm.org/10.1145/3173574.3173831

[26] M. Y. Chan, S. Haber, L. M. Drew, and D. C. Park, "Training Older Adults to Use Tablet Computers: Does It Enhance Cognitive Function?" The Gerontologist, vol. 56, no. 3, pp. 475-484, 062014.

[27] A. Aula, "User study on older adults' use of the web and search engines," Univers. Access Inf. Soc., vol. 4, no. 1, pp. 67-81, Sep. 2005. [Online]. Available: http://dx.doi.org/10.1007/s10209-004-0097-7

[28] A. D. Fisk, W. A. Rogers, N. Charness, S. J. Czaja, and J. Sharit, Designing for older adults: Principles and creative human factors approaches. CRC press, 2009.

[29] W. A. Rogers, A. D. Fisk, S. E. Mead, N. Walker, and E. F. Cabrera, "Training older adults to use automatic teller machines," Human Factors, vol. 38, no. 3, pp. 425-433, 1996, pMID: 8865767. [Online]. Available: https://doi.org/10.1518/001872096778701935

[30] J. M. Hickman, W. A. Rogers, and A. D. Fisk, "Training older adults to use new technology." The journals of gerontology. Series B, Psychological sciences and social sciences, vol. 62 Spec No 1, pp. 77-84, Jun 2007. 
[31] C. Norval, J. L. Arnott, and V. L. Hanson, "What's on your mind?: Investigating recommendations for inclusive social networking and older adults," in Proceedings of the SIGCHI Conference on Human Factors in Computing Systems, ser. CHI '14. New York, NY, USA: ACM, 2014, pp. 3923-3932. [Online]. Available: http://doi.acm.org/10.1145/2556288.2556992

[32] A. Hope, T. Schwaba, and A. M. Piper, "Understanding digital and material social communications for older adults," in Proceedings of the SIGCHI Conference on Human Factors in Computing Systems, ser. CHI '14. New York, NY, USA: ACM, 2014, pp. 3903-3912. [Online]. Available: http://doi.acm.org/10.1145/2556288.2557133

[33] C. D. Stewart, V. L. Hanson, and T. J. Nind, "Assisting older adults in assessing the reliability of health-related websites," in CHI '14 Extended Abstracts on Human Factors in Computing Systems, ser. CHI EA '14. New York, NY, USA: ACM, 2014, pp. 2611-2616. [Online]. Available: http://doi.acm.org/10.1145/2559206.2581243

[34] W. Choi, "What makes online health information credible for older adults?: An exploratory study," in CHI '13 Extended Abstracts on Human Factors in Computing Systems, ser. CHI EA '13. New York, NY, USA: ACM, 2013, pp. 2671-2676. [Online]. Available: http://doi.acm.org/10.1145/2468356.2479491

[35] F. Portet, M. Vacher, C. Golanski, C. Roux, and B. Meillon, "Design and evaluation of a smart home voice interface for the elderly: Acceptability and objection aspects," Personal Ubiquitous Comput., vol. 17, no. 1, pp. 127-144, Jan. 2013. [Online]. Available: http://dx.doi.org/10.1007/s00779-011-0470-5

[36] G. Demiris, D. P. Oliver, G. Dickey, M. Skubic, and M. Rantz, "Findings from a participatory evaluation of a 
smart home application for older adults," Technol. Health Care, vol. 16, no. 2, pp. 111-118, Apr. 2008. [Online]. Available: http://dl.acm.org/citation.cfm?id=1378666.1378670

[37] M. A. O'brien, W. A. Rogers, and A. D. Fisk, "Understanding age and technology experience differences in use of prior knowledge for everyday technology interactions," ACM Trans. Access. Comput., vol. 4, no. 2, pp. 9:1-9:27, Mar. 2012. [Online]. Available: http://doi.acm.org/10.1145/2141943.2141947

[38] S. Chiasson and C. Gutwin, "Design principles for children's software," Tech. Rep. HCI-TR-05-02, 2005.

[39] N. Soni, A. Aloba, K. S. Morga, P. J. Wisniewski, and L. Anthony, "A framework of touchscreen interaction design recommendations for children (tidrc): Characterizing the gap between research evidence and design practice," in Proceedings of the 18th ACM International Conference on Interaction Design and Children, ser. IDC '19. New York, NY, USA: ACM, 2019, pp. 419-431. [Online]. Available: http://doi.acm.org/10.1145/3311927.3323149

[40] M. Bakaev, "Fitts' law for older adults: Considering a factor of age," in Proceedings of the VIII Brazilian Symposium on Human Factors in Computing Systems, ser. IHC '08. Porto Alegre, Brazil, Brazil: Sociedade Brasileira de Computa\&\#231;\&\#227;o, 2008, pp. 260-263. [Online]. Available: http://dl.acm.org/citation.cfm?id=1497470.1497502

[41] S. Keates and S. Trewin, "Effect of age and parkinson's disease on cursor positioning using a mouse," in Proceedings of the 7th International ACM SIGACCESS Conference on Computers and Accessibility, ser. Assets '05. New York, NY, USA: ACM, 2005, pp. 68-75. [Online]. Available: http://doi.acm.org/10.1145/1090785.1090800 
[42] M. Zajicek, "Interface design for older adults," in Proceedings of the 2001 EC/NSF Workshop on Universal Accessibility of Ubiquitous Computing: Providing for the Elderly, ser. WUAUC'01. New York, NY, USA: ACM, 2001, pp. 60-65. [Online]. Available: http://doi.acm.org/10.1145/564526.564543

[43] A. Darejeh and D. Valbir Singh, "A review on user interface design principles to increase software usability for users with less computer literacy," Journal of Computer Science, vol. 9, no. 11, pp. 1443-1450, 2013.

[44] J. Nielsen and R. Molich, "User interface design guidelines: $\quad 10$ rules of thumb," Apr 1994. [Online]. Available: https://www.interaction-design.org/literature/article/userinterface-design-guidelines-10-rules-of-thumb

[45] B. Shneiderman, Designing the User Interface: Strategies for Effective Human-Computer Interaction, 3rd ed. Boston, MA, USA: AddisonWesley Longman Publishing Co., Inc., 1997.

[46] J. Johnson, Designing with the Mind in Mind: Simple Guide to Understanding User Interface Design Rules. San Francisco, CA, USA: Morgan Kaufmann Publishers Inc., 2010.

[47] D. R. Compeau and C. A. Higgins, "Computer self-efficacy: Development of a measure and initial test," MIS Quarterly, vol. 19, no. 2, pp. 189-211, 1995. [Online]. Available: http://www.jstor.org/stable/249688

[48] O. Friard and M. Gamba, "Boris: A free, versatile open-source eventlogging software for video/audio coding and live observations," Methods in Ecology and Evolution, vol. 7, 052016.

[49] C. N. Harada, M. N. Love, and K. L. Triebel, "Normal cognitive aging." Clinics in geriatric medicine, vol. 29 4, pp. 737-52, 2013. 
[50] J. Matejka, T. Grossman, and G. Fitzmaurice, "Patina: Dynamic heatmaps for visualizing application usage," in Proceedings of the SIGCHI Conference on Human Factors in Computing Systems, ser. CHI '13. New York, NY, USA: ACM, 2013, pp. 3227-3236. [Online]. Available: http://doi.acm.org/10.1145/2470654.2466442

[51] S. Malacria, G. Bailly, J. Harrison, A. Cockburn, and C. Gutwin, "Promoting hotkey use through rehearsal with exposehk," in Proceedings of the SIGCHI Conference on Human Factors in Computing Systems, ser. CHI '13. New York, NY, USA: ACM, 2013, pp. 573-582. [Online]. Available: http://doi.acm.org/10.1145/2470654.2470735

[52] Y. S. Yoon and B. A. Myers, "Supporting selective undo in a code editor," in Proceedings of the 37th International Conference on Software Engineering - Volume 1, ser. ICSE '15. Piscataway, NJ, USA: IEEE Press, 2015, pp. 223-233. [Online]. Available: http://dl.acm.org/citation.cfm?id=2818754.2818784

[53] B. A. Myers, A. Lai, T. M. Le, Y. Yoon, A. Faulring, and J. Brandt, "Selective undo support for painting applications," in Proceedings of the 33rd Annual ACM Conference on Human Factors in Computing Systems, ser. CHI '15. New York, NY, USA: ACM, 2015, pp. 4227-4236. [Online]. Available: http://doi.acm.org/10.1145/2702123.2702543

[54] C. A. Fraser, M. Dontcheva, H. Winnemöller, S. Ehrlich, and S. Klemmer, "Discoveryspace: Suggesting actions in complex software," in Proceedings of the 2016 ACM Conference on Designing Interactive Systems, ser. DIS '16. New York, NY, USA: ACM, 2016, pp. 1221-1232. [Online]. Available: http://doi.acm.org/10.1145/2901790.2901849 


\section{Appendix}

This appendix contains all the resources that were used to conduct the user study discussed in Chapter 3.

\section{Call for Participation}




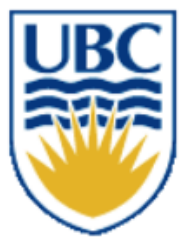

Department of Computer Science

University of British Columbia

Vancouver, BC, V6T $1 Z 4$

\section{Are you a first-time user of Microsoft OneNote? If yes, come to take part in this paid study!}

\section{Who are we?}

We are researchers from the University of British Columbia: Dr. Joanna McGrenere, and Shareen Mahmud. We are conducting a study to identify individual differences in exploratory learning styles when learning to use Microsoft OneNote for the first time.

\section{We are looking for participants who ...}

- are children (10-12), adults (20-35), or older adults (60-75)

- are free of diagnosed cognitive impairments or motor impairments to their hands

- are first time users of Microsoft OneNote

\section{What is involved?}

You will carry out a set of tasks using Microsoft OneNote on a laptop, at a location of your choice in Vancouver. After that, you will be interviewed about your experience using the application. The study is expected to take about an hour.

\section{Receive a $\$ 20$ honorarium for per hour}

\section{Interested in Participating?}

If you are interested in participating or would like more information, please contact Shareen at 
Consent Forms 


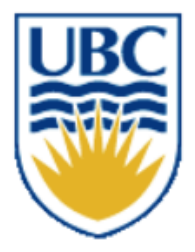

\title{
THE UNIVERSITY OF BRITISH COLUMBIA
}

\author{
Department of Computer Science \\ 2366 Main Mall \\ Vancouver, B.C., V6T 1 Z4
}

\section{Consent Form}

\section{Designing and Evaluating Personalized Interfaces to Support Individual Differences in Exploratory Learning Styles}

\section{Principal Investigator:}

Joanna McGrenere, Professor, Department of Computer Science, University of British Columbia

\section{Co-Principal Investigator:}

Shareen Mahmud, MSc student, Department of Computer Science, University of British Columbia

\section{What the study is about:}

The overall purpose of this research is to identify the individual differences in users' exploratory learning styles when learning to use a feature-rich application for the first time.

What you will be asked to do: After you have read this document, I will respond to any questions or concerns that you may have. Once you have signed this consent form, you will be asked to:

- interact with a feature-rich application such as Microsoft OneNote

- $\quad$ answer interview questions

This should take approximately 45 minutes to 1 hour and be completed in 1 session.

The session may also be audio recorded as you interact with the application. You have the option not to be audio recorded. Your eye gaze may be recorded by an eye tracker attached to the laptop.

Inclusion criteria: We are looking for participants who:

- are children, adults, or older adults

- are free of diagnosed cognitive impairments or motor impairments to their hands

- are first time users of Microsoft OneNote 
Risks and Benefits: There are no known psychological, physical, and social risks involved in the proposed research. Participants may learn how to benefit by learning about different features of Microsoft OneNote.

How the data collected will be used: Data collected (including any audio recordings) will be used for analysis. This analysis will help us extract requirements for a personalized user interface of Microsoft OneNote. The research findings from this data may also be used to publish scholarly articles in conferences or journals.

Compensation: You will receive \$20 honorarium for this one hour study. The compensation will be provided prior to the study as cash only.

Confidentiality: The results of your participation will be reported without any reference to you specifically. All information that you provide will be stored in Canada. Only the researchers involved in this research will have access to the data.

Your data may be used but will remain anonymous in any reports, research papers, thesis documents, and presentations that result from this work. Your name will never be used, only a code associated with the data. Any identifiable element in the audios will be obscured to prevent identification. The only link between the code associated and your actual name will be this consent form and a printed spreadsheet, that will be stored in a locked cabinet, in a research lab with controlled access at UBC. The file linking your name with the associated code will be kept separate from the data.

Data Retention: All electronic files will be stored in an encrypted hard drive of a password-protected laptop. Backups of the data will be stored on the UBC Computer Science secure department servers. Any handwritten notes and paper transcripts will be kept in a locked cabinet in the Principal Investigator's office with controlled access at UBC. Five years after the completion of the research, the electronic data will be deleted, and all physical media, audio records, and paper transcripts will be shredded by the Principal Investigator.

Taking part is voluntary: Your participation is voluntary. You are free to stop your participation at any point. Refusal to participate or withdrawal of your consent or discontinued participation in the study will not result in any penalty or loss of benefits or rights to which you might otherwise be entitled.

\section{Ethical Concerns and Participant Rights}

If you have any concerns or complaints about your rights as a research participant and/or your experiences while participating in this study, contact the Research Participant Complaint Line in the UBC Office of Research Ethics at 604-822-8598 or if long distance e-mail RSIL@ors.ubc.ca or call toll free 1-877-822-8598. 
Please tick one of the following

$\square$ I consent to be audio recorded in this study

$\square$ I do not consent to be audio recorded in this study

I, have read the explanation about this study. I have been given the opportunity to discuss it and my questions have been answered to my satisfaction. I hereby consent to take part in this study. However, I realize that my participation is voluntary and that I am free to withdraw at any time.

Participant's Signature

Date 


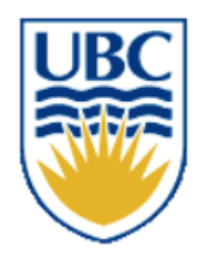

\title{
THE UNIVERSITY OF BRITISH COLUMBIA
}

\author{
Department of Computer Science \\ 2366 Main Mall \\ Vancouver, B.C., V6T 1 Z4
}

\section{Parental Consent Form}

\section{Designing and Evaluating Personalized Interfaces to Support Individual Differences in Exploratory Learning Styles}

\section{Principal Investigator:}

Joanna McGrenere, Professor, Department of Computer Science, University of British Columbia

\section{Co-Principal Investigator:}

Shareen Mahmud, MSc student, Department of Computer Science, University of British Columbia

\section{What the study is about:}

The overall purpose of this research is to identify the individual differences in users' exploratory learning styles when learning to use a feature-rich application for the first time.

What will your child be asked to do: After you have read this document, I will respond to any questions or concerns that you may have. Once you have signed this consent form, your child will be asked to:

- interact with a feature-rich application such as Microsoft OneNote

- answer interview questions

This should take approximately 45 minutes to 1 hour and be completed in 1 session.

The session may also be audio recorded. You have the option to not let your child's session be audio recorded. Your child's eye gaze may be recorded by an eye tracker attached to the laptop.

Inclusion criteria: We are looking for participants who:

- are children

- are free of diagnosed cognitive impairments or motor impairments to their hands

- are first time users of Microsoft OneNote 
Risks and Benefits: There are no known psychological, physical, and social risks involved in the proposed research. Participants may learn how to benefit by learning about different features of Microsoft OneNote.

How the data collected will be used: Data collected (including any audio recordings) will be used for analysis. This analysis will help us extract requirements for a personalized user interface of Microsoft OneNote. The research findings from this data may also be used to publish scholarly articles in conferences or journals.

Compensation: Your child will receive \$20 honorarium for this one hour study. The compensation will be provided prior to the study as cash only.

Confidentiality: The results of your child's participation will be reported without any reference to you or your child specifically. All the information that your child provides will be stored in Canada. Only the researchers involved in this research will have access to the data.

Your child's data may be used but will remain anonymous in any reports, research papers, thesis documents, and presentations that result from this work. Your child's name will never be used, only a code associated with the data. Any identifiable element in the audios will be obscured to prevent identification. The only link between the code associated and your child's actual name will be this consent form and a printed spreadsheet, that will be stored in a locked cabinet, in a research lab with controlled access at UBC. The file linking your child 's name with the associated code will be kept separate from the data.

Data Retention: All electronic files will be stored in an encrypted hard drive of a password-protected laptop. Backups of the data will be stored on the UBC Computer Science secure department servers. Any handwritten notes and paper transcripts will be kept in a locked cabinet in the Principal Investigator's office with controlled access at UBC. Five years after the completion of the research, the electronic data will be deleted, and all physical media, audio records, and paper transcripts will be shredded by the Principal Investigator.

Taking part is voluntary: Your child's participation is voluntary. You are free to stop your child's participation at any point. Refusal to participate or withdrawal of your consent or discontinue participation of your child in the study will not result in any penalty or loss of benefits or rights to which your child might otherwise be entitled.

\section{Ethical Concerns and Participant Rights}

If you have any concerns or complaints about your child's rights as a research participant and/or your child's experiences while participating in this study, contact the Research Participant Complaint Line in the UBC Office of Research Ethics at 604-822-8598 or if long distance e-mail RSIL@ors.ubc.ca or call toll free 1-877-822-8598. 
Please tick one of the following

$\downarrow$ I consent for my child to be audio recorded in this study

$\downarrow$ I do not consent for my child to be audio recorded

I, _L have read the explanation about this study. I have been given the opportunity to discuss it and my questions have been answered to my satisfaction. I hereby consent for my child to take part in this study. However, I realize that my child's participation is voluntary and that my child is free to withdraw at any time.

Parent's Signature

Date 
Conceptual Model 
OneNote is a digital notebook that has the properties of a physical notebook.

A Physical Notebook

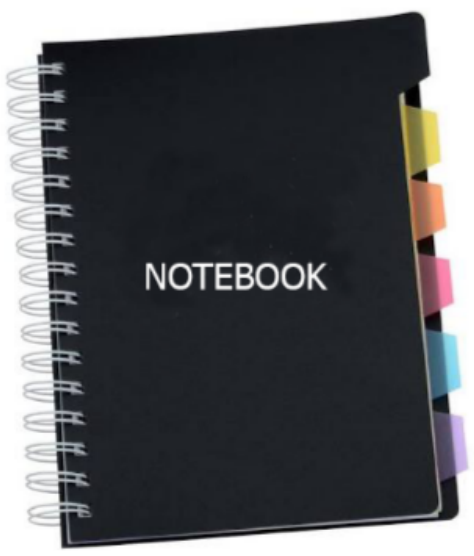

Each notebook has multiple colored sections that can be used to organize different topics

Colored Sections

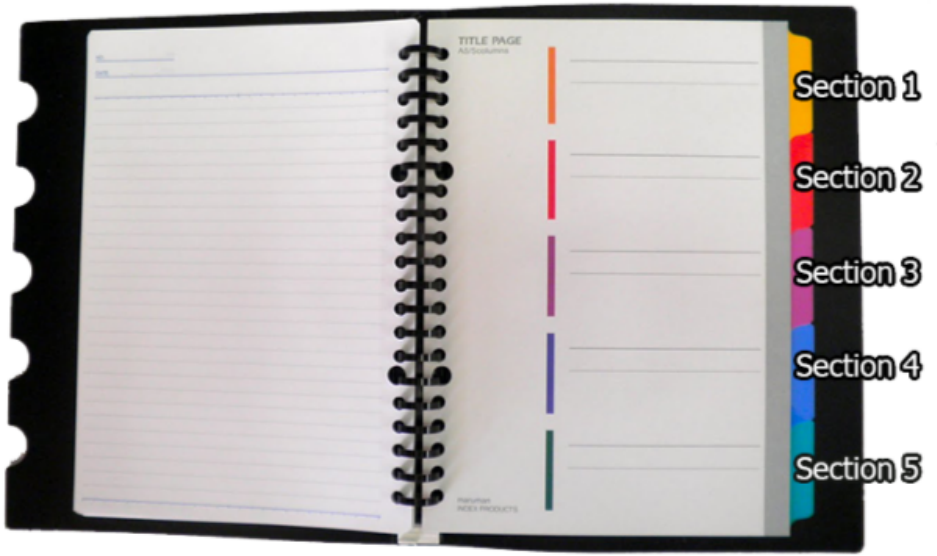

Each section can have one or more pages in order to organize different ideas related to the same topic. 


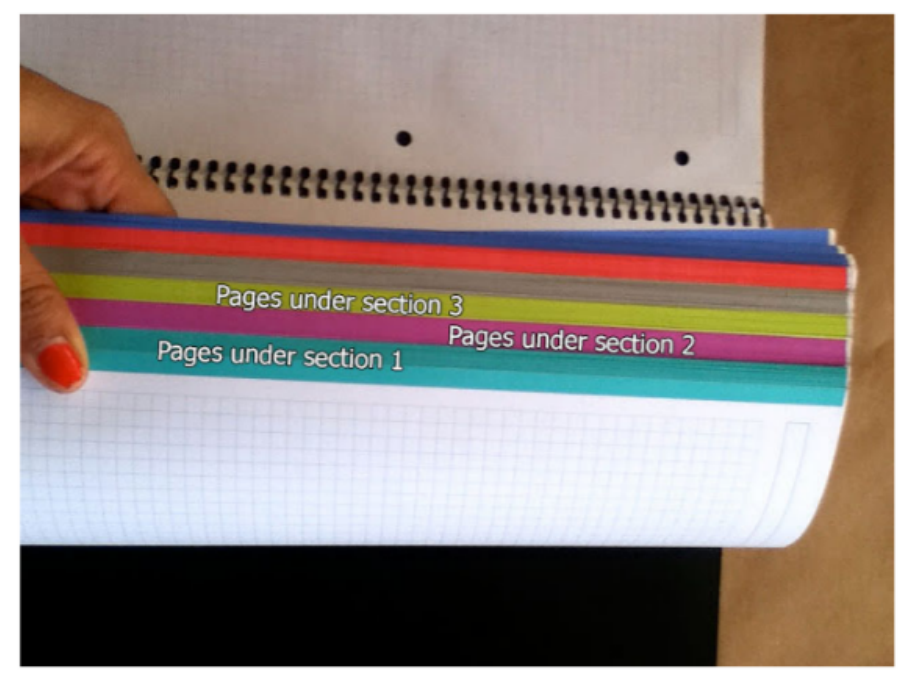

The digital notebook has various tools such as pens, pencils, erasers, highlighters, etc that can be used for note-taking.

Note-taking tools

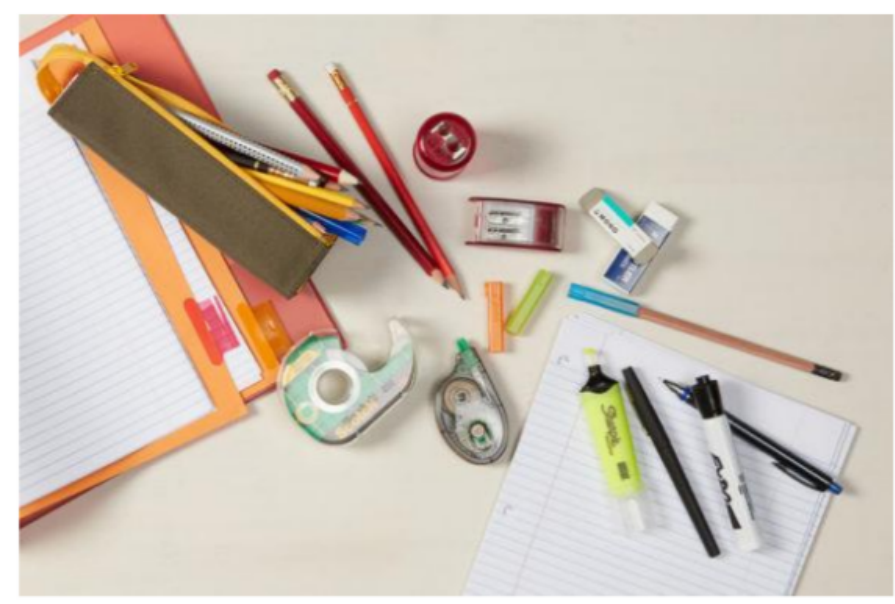

Images from:

http://pocketblonde. blogspotcom/2011/10/maruman-5-section-binder.htm/

httto://scribblewithapen blogspot com/2012/10/miquelrius. $\mathrm{htm}$

https://thewirecutter.com/reviews/best-school-supplies/ 
Task List 
Imagine you have enrolled for two online classes this year because you have an interest in Art and Science. You maintain a notebook on Microsoft OneNote where you regularly take notes for your online classes. You have also shared this notebook with a friend who loves art and science, too.

The following steps will allow you to create, update, and share your notebook. You are advised to carry them out using only OneNote and without taking external help from the web. Please complete them at your own pace.

- Create a notebook called 'Online Class 2018'

- Add a section called 'Art'

- Create a page under the 'Art' section and name it with today's date

- On this page, start taking notes by typing the name of today's topic as 'Flowers'

- Highlight the topic name in yellow

- Add an online picture of a flower to this page as a reference image

- Draw a flower similar to the picture you chose above

- Change the background color of this page from white to orange

Now, let's move on to the Science class

- Add a section called 'Science'

- Create a page under the 'Science' section and name it with today's date

- On this page, start taking notes by typing the name of today's topic as 'Polar Bear'

- Find information about Polar Bear within OneNote and add the information from the first source that you see

- Secure the 'Science' section by locking it with a password of your choice

- Share your 'Online Class 2018' notebook with your friend whose email id is: 
Expertise Questionnaire 
Your Name

Which age group do you belong to?
O $10 \cdot 12$
O 13.19
O $20-25$
O $26 \cdot 30$
O $31-35$
O 36.59
O $60-65$
O $66 \cdot 70$
O $71 \cdot 75$
76 and above

For each of the devices below, please indicate the number of years that you have used each.

\begin{tabular}{|c|c|c|c|c|c|c|c|c|}
\hline & Never & $\begin{array}{l}\text { Less } \\
\text { than } 1 \\
\text { year }\end{array}$ & $\begin{array}{l}1.2 \\
\text { years }\end{array}$ & $\begin{array}{l}3-4 \\
\text { years }\end{array}$ & $\begin{array}{l}5 \cdot 7 \\
\text { years }\end{array}$ & $\begin{array}{l}8-10 \\
\text { years }\end{array}$ & $\begin{array}{c}11 \\
\text { years } \\
\text { and } \\
\text { above }\end{array}$ & $\begin{array}{l}\text { I am } \\
\text { not } \\
\text { sure }\end{array}$ \\
\hline $\begin{array}{l}\text { Desktop Computer (e.g., } \\
\text { iMAC, Windows PC) }\end{array}$ & 0 & 0 & 0 & 0 & $\mathrm{O}$ & 0 & 0 & 0 \\
\hline $\begin{array}{l}\text { Laptop (e.g., MacBook, } \\
\text { Microsoft Surface) }\end{array}$ & 0 & 0 & 0 & 0 & $\mathrm{O}$ & 0 & 0 & 0 \\
\hline $\begin{array}{l}\text { Tablet (e.g., iPad, } \\
\text { Samsung Galaxy Tab) }\end{array}$ & 0 & 0 & 0 & 0 & 0 & 0 & 0 & 0 \\
\hline $\begin{array}{l}\text { Smartphone (e.g., } \\
\text { iPhone, Android) }\end{array}$ & $\mathrm{O}$ & O & 0 & O & $\mathrm{O}$ & $\mathrm{O}$ & $\mathrm{O}$ & 0 \\
\hline
\end{tabular}


On an average, how many hours a day do you spend using each of the devices below?

\begin{tabular}{|c|c|c|c|c|c|c|c|}
\hline & $\begin{array}{l}\text { I don't } \\
\text { use it }\end{array}$ & $\begin{array}{c}\text { Less } \\
\text { than } 1 \\
\text { hour }\end{array}$ & $\begin{array}{l}1 \cdot 2 \\
\text { hours }\end{array}$ & $\begin{array}{l}3 \cdot 4 \\
\text { hours }\end{array}$ & $\begin{array}{l}5 \cdot 6 \\
\text { hours }\end{array}$ & $\begin{array}{l}7 \cdot 8 \\
\text { hours }\end{array}$ & $\begin{array}{l}9 \text { hours } \\
\text { and } \\
\text { more }\end{array}$ \\
\hline $\begin{array}{l}\text { Desktop Computer (e.g., } \\
\text { iMAC, Windows PC) }\end{array}$ & $\mathrm{O}$ & 0 & 0 & 0 & 0 & $\mathrm{O}$ & 0 \\
\hline $\begin{array}{l}\text { Laptop (e.g., MacBook, } \\
\text { Microsoft Surface) }\end{array}$ & $\mathrm{O}$ & 0 & $\mathrm{O}$ & 0 & $\mathrm{O}$ & $\mathrm{O}$ & 0 \\
\hline $\begin{array}{l}\text { Tablet (e.g., iPad, } \\
\text { Samsung Galaxy Tab) }\end{array}$ & $\mathrm{O}$ & 0 & $\mathrm{O}$ & $\mathrm{O}$ & $\mathrm{O}$ & $\mathrm{O}$ & $\mathrm{O}$ \\
\hline $\begin{array}{l}\text { Smartphone (e.g., } \\
\text { iPhone, Android) }\end{array}$ & 0 & 0 & $\mathrm{O}$ & $\mathrm{O}$ & $\mathrm{O}$ & $\mathrm{O}$ & 0 \\
\hline
\end{tabular}

How would you define your skill with each of the devices below?

$\begin{array}{lccc} & \text { Beginner } & \text { Intermediate } & \text { Expert } \\ \begin{array}{l}\text { Desktop Computer (e.g., } \\ \text { iMAC, Windows PC) }\end{array} & 0 & 0 & 0 \\ \begin{array}{l}\text { Laptop (e.g., MacBook, } \\ \text { Microsoft Surface) }\end{array} & 0 & 0 & 0 \\ \begin{array}{l}\text { Tablet (e.g., iPad, } \\ \text { Samsung Galaxy Tab) }\end{array} & 0 & 0 & 0 \\ \begin{array}{l}\text { Smartphone (e.g., } \\ \text { iPhone, Android) }\end{array} & 0 & 0 & 0\end{array}$

Which of these operating systems have you used on a computer? Select all that apply.

$\square$ Windows
$\square$ Mac
$\square$ Linux
$\square$ I am not sure


Approximately, how often do you use the following applications?

$\begin{array}{lcccccc} & \text { Never } & \text { Rarely } & \text { Daily } & \text { Weekly } & \text { Monthly } & \begin{array}{c}\text { I am not } \\ \text { sure }\end{array} \\ \begin{array}{l}\text { Productivity (e.g., } \\ \text { Microsoft Word, Google } \\ \text { Docs) }\end{array} & 0 & 0 & 0 & 0 & 0 & 0 \\ \begin{array}{l}\text { Spreadsheet (e.g., } \\ \text { Microsoft Excel, Google }\end{array} & 0 & 0 & 0 & 0 & 0 & 0 \\ \begin{array}{l}\text { Spreadsheet) } \\ \text { Microsoft OneNote }\end{array} & 0 & 0 & 0 & 0 & 0 & 0 \\ \begin{array}{l}\text { Evernote } \\ \begin{array}{l}\text { Other Note-taking } \\ \text { applications (e.g., } \\ \text { Notepad, Simplenote) }\end{array}\end{array} & 0 & 0 & 0 & 0 & 0 & 0 \\ \begin{array}{l}\text { Email (e.g., Gmail, } \\ \text { Yahoo) }\end{array} & 0 & 0 & 0 & 0 & 0 & 0 \\ \begin{array}{l}\text { Presentation (e.g., } \\ \text { PowerPoint, Keynote, } \\ \text { Google Slides) }\end{array} & 0 & 0 & 0 & 0 & 0 & 0 \\ \begin{array}{l}\text { Social Media (e.g., } \\ \text { Facebook, Whatsapp, } \\ \text { Instagram, Viber) }\end{array} & 0 & 0 & 0 & 0 & 0 & 0\end{array}$


What is your current employment status?
Omployed full-time (35 or more hours per week)
Employed part-time (less than 35 hours per week)
O Unemployed
O Student
Homemaker
O Self-employed
Retired

For each of the applications below, please indicate the number of years that you have used each (or had used each if you no longer use that application)

\begin{tabular}{|c|c|c|c|c|c|c|c|c|}
\hline & Never & $\begin{array}{l}\text { Less } \\
\text { than } 1 \\
\text { year }\end{array}$ & $\begin{array}{c}1-2 \\
\text { years }\end{array}$ & $\begin{array}{c}3-4 \\
\text { years }\end{array}$ & $\begin{array}{l}5-7 \\
\text { years }\end{array}$ & $\begin{array}{l}8-10 \\
\text { years }\end{array}$ & $\begin{array}{c}11 \\
\text { years } \\
\text { and } \\
\text { above }\end{array}$ & $\begin{array}{l}\text { I am } \\
\text { not } \\
\text { sure }\end{array}$ \\
\hline $\begin{array}{l}\text { Word Processor (e.g., } \\
\text { Microsoft Word, Google } \\
\text { Docs) }\end{array}$ & 0 & 0 & 0 & 0 & 0 & 0 & 0 & 0 \\
\hline $\begin{array}{l}\text { Spreadsheet (e.g., } \\
\text { Microsoft Excel, Google } \\
\text { Spreadsheet) }\end{array}$ & 0 & 0 & 0 & 0 & 0 & 0 & 0 & 0 \\
\hline Evernote & 0 & 0 & 0 & 0 & 0 & 0 & 0 & 0 \\
\hline $\begin{array}{l}\text { Other Note-taking } \\
\text { applications (e.g., } \\
\text { Notepad, Simplenote) }\end{array}$ & O & 0 & 0 & 0 & 0 & 0 & 0 & 0 \\
\hline $\begin{array}{l}\text { Email (e.g., Gmail, } \\
\text { Yahoo) }\end{array}$ & 0 & 0 & 0 & 0 & 0 & 0 & 0 & 0 \\
\hline $\begin{array}{l}\text { Presentation (e.g., } \\
\text { PowerPoint, Keynote, } \\
\text { Google Slides) }\end{array}$ & 0 & 0 & 0 & 0 & 0 & 0 & 0 & 0 \\
\hline $\begin{array}{l}\text { Social Media (e.g., } \\
\text { Facebook, Whatsapp, } \\
\text { Instagram, Viber) }\end{array}$ & 0 & 0 & 0 & 0 & 0 & 0 & 0 & 0 \\
\hline
\end{tabular}


Approximately, how often had you used the following applications over the 6 months prior to taking part in our study?

$\begin{array}{lccccc} & \text { Never } & \text { Rarely } & \text { Monthly } & \text { Weekly } & \text { Daily } \\ \begin{array}{l}\text { Word Processor (e.g., } \\ \text { Microsoft Word, Google } \\ \text { Docs) }\end{array} & 0 & 0 & 0 & 0 & 0 \\ \begin{array}{l}\text { Spreadsheet (e.g., } \\ \text { Microsoft Excel, Google } \\ \text { Spreadsheet) }\end{array} & 0 & 0 & 0 & 0 & 0 \\ \begin{array}{l}\text { Evernote } \\ \begin{array}{l}\text { Other Note-taking } \\ \text { applications (e.g., } \\ \text { Notepad, Simplenote) }\end{array}\end{array} & 0 & 0 & 0 & 0 & 0 \\ \begin{array}{l}\text { Email (e.g., Gmail, } \\ \text { Yahoo) }\end{array} & 0 & 0 & 0 & 0 & 0 \\ \begin{array}{l}\text { Presentation (e.g., } \\ \text { PowerPoint, Keynote, } \\ \text { Google Slides) }\end{array} & 0 & 0 & 0 & 0 & 0 \\ \begin{array}{l}\text { Social Media (e.g., } \\ \text { Facebook, Whatsapp, } \\ \text { Instagram, Viber) }\end{array} & 0 & 0 & 0 & 0 & 0\end{array}$


Self-Efficacy Questionnaire 
The following questions ask you to indicate to what extent you feel that you could use an unfamiliar notetaking application -- such a Microsoft OneNote -- under a variety of conditions. For each of the conditions, please indicate whether you think you would be able to complete the tasks using a notetaking application. Then, for each condition that you answered "yes," please rate your confidence about your first judgment, by entering a number from 1 to 10 where 1 indicates "Not at all confident", 5 indicates "Moderately confident", and 10 indicates "Totally confident"

Given a notetaking application (such as Microsoft OneNote), I could use it to create and maintain notes...

Q1 ..if there was no one around to tell me what to do as I go

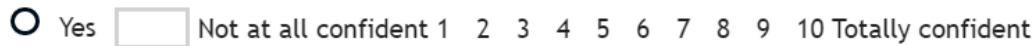

No

Q2 ..if I had never used an application like it before

$\begin{array}{lllllllllll} & \text { Yes } \square \text { Not at all confident } 1 & 2 & 3 & 4 & 5 & 6 & 7 & 8 & 9 & 10 \text { Totally confident }\end{array}$

O No

Q3 ..if I had only the application manual for reference

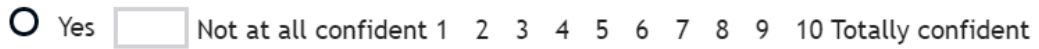
O No 
Q4 ..if I had seen someone else using the application before trying it myself

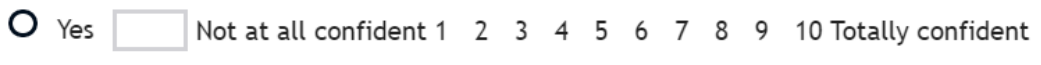
No

Q5 ..if I could call someone for help if I got stuck

O Yes $\square$ Not at all confident 1 \begin{tabular}{llllllllll}
\hline & 2 & 3 & 4 & 5 & 6 & 7 & 8 & 9 & 10 Totally confident
\end{tabular} O No

Q6 ..if someone else had helped me get started with the application O Yes $\square$ Not at all confident $1 \begin{array}{llllllllll}1 & 2 & 3 & 4 & 5 & 6 & 7 & 8 & 9 & 10 \text { Totally confident }\end{array}$ O No

Q7 ..if I had a lot of time to complete the tasks for which the application was provided

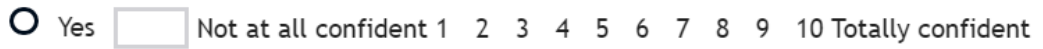
O No

Q8 ..if I had just the built-in help facility for assistance

O Yes $\square$ Not at all confident $1 \begin{array}{llllllllll} & 2 & 3 & 4 & 5 & 6 & 7 & 8 & 9 & 10 \text { Totally confident }\end{array}$ O No

Q9 ..if I could take help from the web

$\begin{array}{lllllllllll}O & \text { Yes } \square \text { Not at all confident } 1 & \square & 3 & 4 & 5 & 6 & 7 & 8 & 9 & 10 \text { Totally confident }\end{array}$ O No 
Q10 ..if someone showed me how to do the tasks first

$\begin{array}{lllllllllll} & \text { Yes } \square \text { Not at all confident } 1 & \square & 3 & 4 & 5 & 6 & 7 & 8 & 9 & 10 \text { Totally confident }\end{array}$ No

Q11 ..if I had used similar applications before this one to do the same tasks

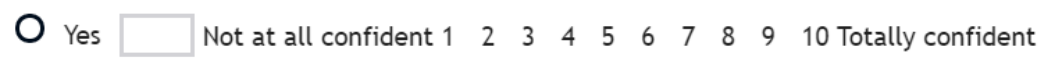

O No 